\title{
Concurrent changes in photoperiod-induced seasonal phenotypes and hypothalamic CART peptide-containing systems in night-migratory redheaded buntings
}

\author{
Omprakash Singh ${ }^{1,2} \cdot$ Neha Agarwal $^{3,4} \cdot$ Anupama Yadav $^{3} \cdot$ Sumela Basu $^{1,2} \cdot$ Shalie Malik ${ }^{3} \cdot$ Sangeeta Rani $^{3}$. \\ Vinod Kumar ${ }^{4}$ Praful S. Singru, ${ }^{1,2}$
}

Received: 10 March 2020 / Accepted: 4 October 2020 / Published online: 3 November 2020

(c) Springer-Verlag GmbH Germany, part of Springer Nature 2020

\begin{abstract}
This study tested the hypothesis whether hypothalamic cocaine-and amphetamine-regulated transcript (CART)-containing systems were involved in photoperiod-induced responses associated with spring migration (hyperphagia and weight gain) and reproduction (gonadal maturation) in migratory songbirds. We specifically chose CART to examine neural mechanism(s) underlying photoperiod-induced responses, since it is a potent anorectic neuropeptide and involved in the regulation of changes in the body mass and reproduction in mammals. We first studied the distribution of CART-immunoreactivity in the hypothalamus of migratory redheaded buntings (Emberiza bruniceps). CART-immunoreactive neurons were found extensively distributed in the preoptic, lateral hypothalamic (LHN), anterior hypothalamic (AN), suprachiasmatic (SCN), paraventricular (PVN), dorsomedialis hypothalami (DMN), inferior hypothalamic (IH), and infundibular (IN) nuclei. Then, we correlated hypothalamic CART-immunoreactivity in buntings with photostimulated seasonal states, particularly winter non-migratory/non-breeding (NMB) state under short days, and spring premigratory/pre-breeding (PMB) and migratory/ breeding (MB) states under long days. There were significantly increased CART-immunoreactive cells, and percent fluorescent area of CART-immunoreactivity was significantly increased in all mapped hypothalamic areas, except the SCN, PVN, $\mathrm{AN}$, and DMN in photostimulated PMB and MB states, as compared to the non-stimulated NMB state. In particular, CART was richly expressed in the medial preoptic nucleus, LHN, IH and IN during MB state in which buntings showed reduced food intake and increased night-time activity. These results suggest that changes in the activity of the CART-containing system in different brain regions were associated with heightened energy needs of the photoperiod-induced seasonal responses during spring migration and reproduction in migratory songbirds.
\end{abstract}

Keywords Cocaine- and amphetamine-regulated transcript $\cdot$ E. bruniceps $\cdot$ Energy balance $\cdot$ Hypothalamus $\cdot$ Migration

Omprakash Singh and Neha Agarwal contributed equally to the work.

Vinod Kumar

drvkumar11@gmail.com

Praful S. Singru

pssingru@niser.ac.in

1 School of Biological Sciences, National Institute of Science Education and Research (NISER), Bhubaneswar,

Jatni, Khurda 752050, Odisha, India

2 Homi Bhabha National Institute, Training School Complex, Anushakti Nagar, Mumbai 400094, India

3 Department of Zoology, University of Lucknow, Lucknow 226007, India

4 Department of Zoology, University of Delhi, Delhi 110007, India

$\begin{array}{ll}\text { Abbreviations } \\ \text { AC } & \text { Anterior commissure } \\ \text { AN } & \text { Anterior hypothalamic nucleus } \\ \text { CO } & \text { Optic chiasma } \\ \text { DMN } & \text { Nucleus dorsomedialis hypothalami } \\ \text { DSV } & \text { Ventral supraoptic decussation } \\ \text { GLv } & \text { Nucleus geniculatus lateralis, pars ventralis } \\ \text { IH } & \text { Inferior hypothalamic nucleus } \\ \text { IN } & \text { Hypothalamic infundibular nucleus } \\ \text { LFB } & \text { Lateral forebrain bundle } \\ \text { LHN } & \text { Lateral hypothalamic nucleus } \\ \text { ME } & \text { Median eminence } \\ \text { PON } & \text { Preoptic nucleus } \\ \text { PONa } & \text { Anterior preoptic nucleus } \\ \text { PONm } & \text { Medial preoptic nucleus } \\ \text { PPN } & \text { Periventricular preoptic nucleus }\end{array}$

\section{Abbreviations}

AC Anterior commissure

AN Anterior hypothalamic nucleus

CO Optic chiasma

DMN Nucleus dorsomedialis hypothalami

DSV Ventral supraoptic decussation

GLv Nucleus geniculatus lateralis, pars ventralis

IH Inferior hypothalamic nucleus

IN Hypothalamic infundibular nucleus

LFB Lateral forebrain bundle

LHN Lateral hypothalamic nucleus

ME Median eminence

PON Preoptic nucleus

PONm Medial preoptic nucleus

PPN Periventricular preoptic nucleus 


$\begin{array}{ll}\text { PVN } & \text { Paraventricular nucleus } \\ \text { PVO } & \text { Paraventricular organ } \\ \text { ROT } & \text { Nucleus rotundus } \\ \text { SCN } & \text { Suprachiasmatic nucleus } \\ \text { SCNm } & \text { SCN, medial } \\ \text { SCNv } & \text { SCN, visual } \\ \text { SOv } & \text { Supraoptic nucleus, ventral } \\ \text { TrO } & \text { Optic tract } \\ \text { TSM } & \text { Septopallial mesencephalic tract } \\ \text { v } & \text { Ventricle } \\ \text { VMN } & \text { Nucleus ventromedialis hypothalamic }\end{array}$

\section{Introduction}

The latitudinal avian migrants exhibit distinct photoperiodinduced seasonal migratory and reproductive states. These states can be induced in captive birds by exposing them to appropriate artificial photoperiods. For instance, the exposure to short days (SDs) maintain the winter non-migratory/ non-breeding phenotype (NMB) state, whereas long days (LDs) induce spring/summer premigratory/ prebreeding (PMB) and migratory/ breeding (MB) phenotypes (Kumar et al. 2010). Photostimulated MB phenotype is characterized by the hyperphagia (increased food intake), copious fat deposition, body mass gain and Zugunruhe (migratory nocturnal restlessness in caged birds (Gwinner and Czeschlik 1978; Bairlein 2002), and gonadal maturation (Agatsuma and Ramenofsky 2006; Rani et al. 2006; Trivedi et al. 2014; Mishra et al. 2017).

Photostimulated change in the seasonal phenotype is accompanied with the altered energy homeostasis. Centrally, the changes involve neural pathways, which have not been clearly defined yet. However, in mammals, studies have identified the orexigenic [neuropeptide Y (NPY) and agouti-related protein (AgRP)] and anorexigenic [proopiomelanocortin (POMC) and cocaine- and amphetamineregulated transcript (CART)] peptides with a major role in the regulation of food intake and energy balance (Chronwall et al. 1985; Elmquist et al. 1998; Barsh and Schwartz 2002; Boswell and Dunn 2017). While NPY and AgRP stimulate eating, POMC and CART are anorectic and believed to induce satiety in rodents (Tomaszuk et al. 1996; Kristensen et al. 1998; Lambert et al. 1998; Okumura et al. 2000; Loh et al. 2015).

Although, NPY expression has been shown to correspond to the photostimulation of MB state (Rastogi et al. 2013), it is unknown if CART as a check point of the regulatory peptide network is involved in the energy homeostasis with transition in photostimulated seasonal states. This is intriguing since CART peptide seems highly conserved both in the distribution and function in the brain (Lázár et al. 2004; Calle et al. 2006; Singru et al. 2007; Subhedar et al. 2011; Akash et al.
2014; Singh et al. 2016a). The organization and functional significance of CART have been described in the brain of several non-mammalian vertebrates including teleosts [catfish, Clarias batrachus: (Singru et al. 2007); Clarias gariepinus: (Subhedar et al. 2011), and zebrafish, Danio rerio (Akash et al. 2014)], frogs [Rana esculenta: (Lázár et al. 2004); Xenopus laevis: (Calle et al. 2006)], and birds [zebra finch, Taeniopygia guttata (Singh et al. 2016a; Gutierrez-Ibanez et al. 2016) and pigeon, Columba livia (Gutierrez-Ibanez et al. 2016)]. In addition to energy balance, CART also plays a role in the reproductive regulation (True et al. 2013). In rats, the CART-containing axons innervate $\mathrm{GnRH}$ neurons in the preoptic area (POA), and treatment with CART alters GnRH neuron firing (True et al. 2013).

As in other vertebrates, CART administered intra-cerebroventricularly inhibited food intake in birds (Tachibana et al. 2003; Honda et al. 2007). The hypothalamic CART mRNA expression was downregulated during fasting in chickens (Cai et al. 2015) and CART inhibits fasting-induced-enhanced hypothalamic NPY in zebra finches (Singh et al. 2016a). Importantly, among the hypothalamic pathways involved in the regulation of energy balance, CART seems to be the only neuropeptide whose transcription pattern indicates its functional role in inducing or maintaining the photoperiod-induced changes in body mass (Mercer and Tups 2003). We, therefore, envisaged that the photostimulated hyperphagia and subsequent weight gain, and gonadal development in latitudinal songbird migrants might be correlated with the activity of the hypothalamic CART-containing system. To investigate this, we found Palaearctic-Indian night-migratory male redheaded buntings (Emberiza bruniceps) as an experimental model, since it exhibits seasonal migration and reproduction phenotypes when exposed to programmed photoperiods in the laboratory environment (Rani et al. 2005). Here, we first mapped out the hypothalamic distribution of CART and characterized different CART-containing neuronal populations. Then, we evaluated differences in the expression pattern of CARTcontaining systems in the hypothalamus of buntings between SD-induced NMB, and LD-induced PMB/ MB phenotypes. The prediction was that hypothalamic areas involved in photoneuroendocrine response would show CART immunoreactivity, and that CART would be expressed at higher levels in the mediobasal hypothalamus, the seasonal clock site (Rastogi et al. 2013) of redheaded buntings exhibiting the photostimulated PMB and MB states, compared to the NMB controls.

\section{Materials and methods}

\section{Animals and experiment}

This study was conducted on male redheaded buntings (Emberiza bruniceps) at the Department of Zoology, 
University of Lucknow, Lucknow $\left(27^{\circ} \mathrm{N}, 81^{\circ} \mathrm{E}\right)$, India, in accordance with guidelines of the Institutional Animal Ethics Committee (IAEC, approved protocol number LU/ ZOOL/IAEC/08/17/09). Bunting is an emberizid Palearctic-Indian night migrant, arriving in India $\left(\sim 25^{\circ} \mathrm{N}\right)$ in September/October and returning to its breeding grounds in west Asia $\left(\sim 40^{\circ} \mathrm{N}\right)$ in March/April (Ali and Dillon 1974). It is photoperiodic and exhibits winter non-migratory/ non-breeding phenotype under short days (SD, 8L:16D) and migratory/breeding phenotype following exposure to long days (LD, $\geq 12 \mathrm{~h}$ light per day) (Rani et al. 2005). The experiments were conducted on adult male birds (body mass $=23-26 \mathrm{~g}$; testis volume $=0.78-1.05 \mathrm{~mm}^{3}$ ) that were captured from overwintering flocks in late February 2017. Post-capture, birds were brought to our outdoor aviary $($ size $=3 \times 2.5 \times 2.5 \mathrm{~m})$ and acclimatized for a week to captive conditions under the natural light-dark cycle and temperature. Acclimated birds were moved indoors and maintained in the aviary $($ size $=2.2 \times 1.8 \times 2.8 \mathrm{~m})$ under SD at $20 \pm 2{ }^{\circ} \mathrm{C}$ temperature until the beginning of the experiment. Under SD, buntings remain unstimulated and maintain their photosensitivity (Rani et al. 2005). The birds were provided food (seeds of Setaria italica) and water ad libitum. Adult, male, Sprague-Dawley rats $(n=2,250-270 \mathrm{~g})$ were used for characterization of tyrosine hydroxylase $(\mathrm{TH})$ antibodies (IAEC, NISER, Bhubaneswar approved protocol number NISER/SBS/IAEC/AH-167-119).

Of total 20 birds, 5 were used for the neuroanatomical characterization of CART immunoreactivity in the hypothalamus. The remaining 15 birds were divided in three groups (group I, II and III) of 5 each and used for experimental evaluation of the role of CART in photoperiodic induction of the spring migration and reproduction phenotype. Birds were singly housed (one bird per cage) in activity cages (size $=60 \times 35 \times 45 \mathrm{~cm}$ ) that were individually placed inside photoperiodic boxes $($ size $=75 \times 50 \times 70 \mathrm{~cm})$ and lit by compact fluorescent bulbs (CFL). A schematic of the experimental design is shown in Fig. 1A. Initially, all birds were exposed to 8L:16D $(L=150 \pm 5.0 \mathrm{~lx} ; D=<1 \mathrm{~lx})$, as before and at this time, the birds lacked subcutaneous fat depots, and had normal body mass and small testes. After a week of non-stimulatory SD, group I birds (non-migratory/ non-breeding, NMB) were perfused in the middle of the day (4 $\mathrm{h}$ after light on), while group II and III birds were exposed to long days (LD, 13L:11D) by $5 \mathrm{~h}$ delaying the light end. After 7 days of LD, group II birds (considered equivalent to showing spring pre-migratory/pre-breeding phenotype, PMB; Rastogi et al. 2011, 2013; Singh et al. 2015) were perfused during the middle of day, i.e., $6.5 \mathrm{~h}$ after light on. Group III birds were continued to be on LD until each individual had shown seven nights of nocturnal Zugunruhe (migratory restlessness as evidenced by intense nighttime activity and wing whirring). These birds [considered equivalent to showing spring migratory/breeding phenotype, MB (Rastogi et al. 2011, 2013; Singh et al. 2015)] were also perfused during the middle of the day $(6.5 \mathrm{~h}$ after lights on). We monitored continuously $24 \mathrm{~h}$ activity pattern, and recorded food intake, subjectively scored body fattening, and measured the body mass and testis size as indices of photoperiod-induced behavioral and physiological states.

\section{Monitoring $\mathbf{2 4} \mathrm{h}$ daily activity-rest pattern}

Each activity cage was equipped with two perches positioned at different heights and mounted with a passive infrared motion sensor (Haustier PIR-Melder Intellisense XJ 413 T with $12 \mathrm{~m}\left(40^{\prime}\right)$ range; C \& K Systems, Conrad Electronic, Germany). Each sensor continuously detected the movement of bird in its each cage and transferred it in 10 min bins to separate channels of the computerized data recording system, using software program from the Stanford Software Systems, Stanford, CA, USA. The activity record over experiment duration was graphed (called actogram) and generated as a double plot wherein successive days were plotted both sideways and underneath to give a better visual analysis (Malik et al. 2004; Rani et al. 2006). We calculated hourly activity levels to show $24 \mathrm{~h}$ behavioral response of buntings in photoperiod-induced seasonal states. For this, we first averaged activity for every hour over 7 days for each individual and then mean $( \pm \mathrm{SE})$ was calculated for each group. In addition, the total activity during the day (light period) and night (dark period) as well as during whole $24 \mathrm{~h}$ day was calculated to better illustrate differences in activity behaviour and make statistical comparison between photoperiod-induced seasonal states. The activity counts were first averaged for a specified period $(24 \mathrm{~h}, 13 \mathrm{~L}$ or 11 D) over 7 days for each individual, and then the mean $( \pm S E)$ was calculated for each group.

\section{Measurement of food intake, body mass, fat deposition and testis size}

Food intake was measured for each individual. The cage floor was covered with a paper with extended sides to collect the spillage. A measured quantity of food was provided in food cup and which was removed and weighed after $24 \mathrm{~h}$. This was repeated for two consecutive days, and then averaged. The difference between the amount of food given and food collected (minus feces) gave the amount of food intake by a bird. From this, mean $( \pm \mathrm{SE})$ food intake $(\mathrm{g} / \mathrm{bird} /$ day) for the group was calculated. For body mass, bird was weighed on a top-pan balance to an accuracy of $0.1 \mathrm{~g}$. The subcutaneous body fat was subjectively scored in an index of $0-5(0=$ no subcutaneous fat, $1=$ light fat deposits overlying the muscles and blood vessels are clearly visible, $2=$ heavier fat deposits overlying muscles, with the visible blood vessel, 
A

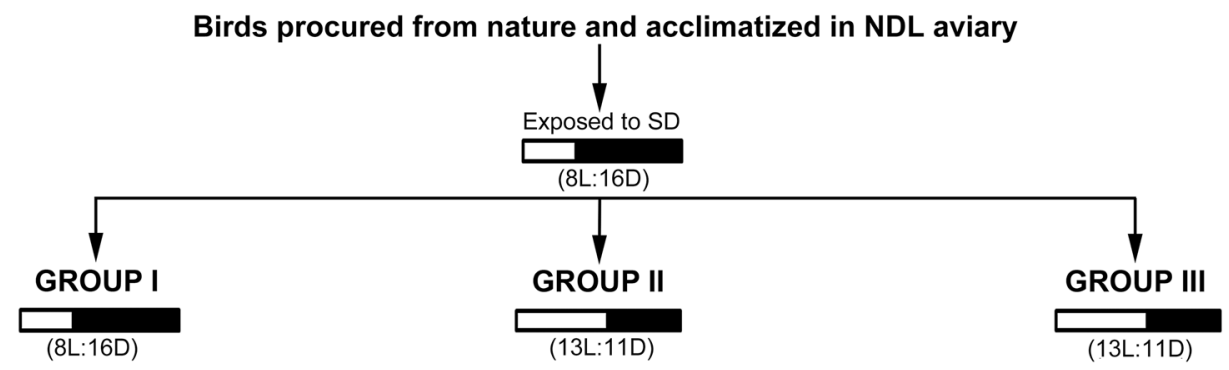

B

B Non-migratory (NMB)

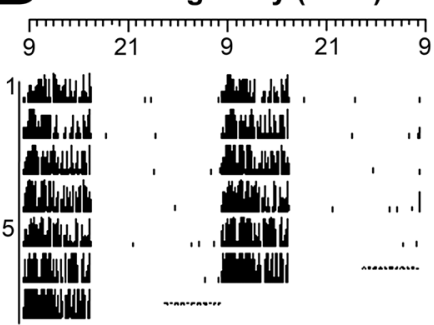

$E$

Day counts

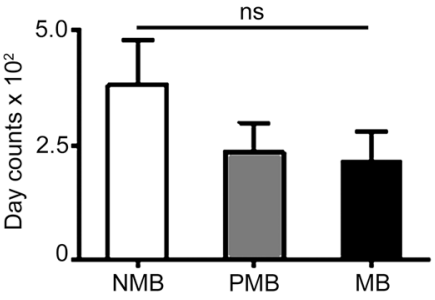

H Activity counts / hours

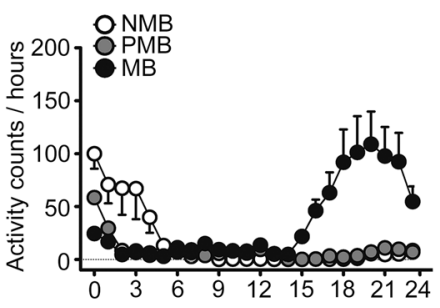

K Testis volume

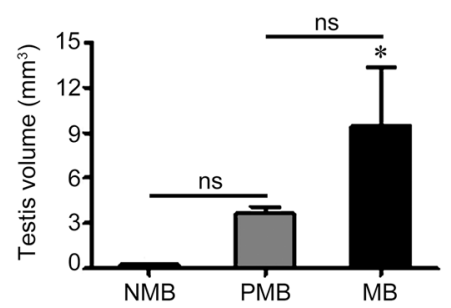

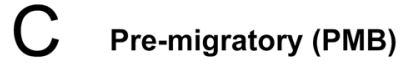

$\begin{array}{llll}9 & 91 & 0\end{array}$

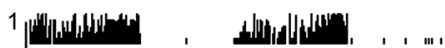

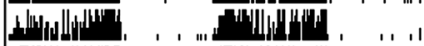

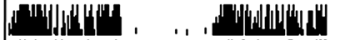

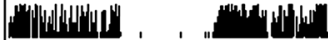

5 mind

(n)

(")"4h

$F$

Night counts

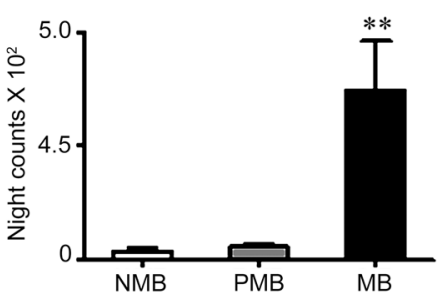

|

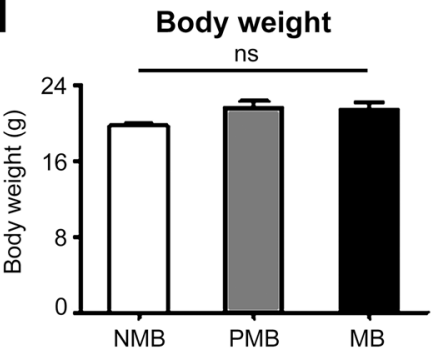

L

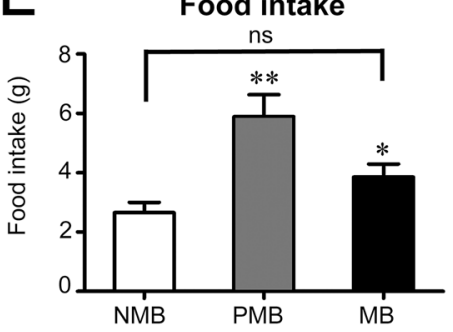

Figure 1
D Migratory (MB)

$\begin{array}{llll}9 & 91 & 9 & 21\end{array}$

1 |w

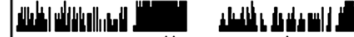
duld

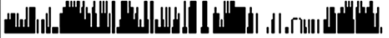

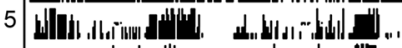

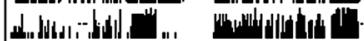

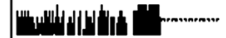

$G$ Total counts

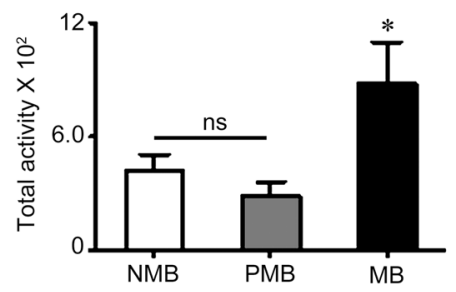

Jat score

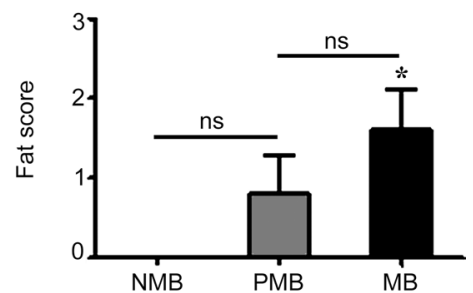


४Fig. 1 A Schematic showing experimental design. Birds acclimatized to short day (SD) [8L: 16D] photoperiodic conditions were divided into three groups ( $n=5 /$ group). The birds in group I were maintained under SD, whereas those in the groups II and III were exposed to long days (LD) [13L:11D]. Group I birds were sacrificed after 1-week exposure to SD and considered as non-migratory/nonbreeding (NMB). Group II birds were sacrificed after 1-week exposure to $\mathrm{LD}$ and considered as pre-migratory/pre-breeding (PMB). The birds in group III were continued LD exposure until each individual showed 7 cycles of nocturnal activity or Zugunruhe. These birds were considered as migratory/breeding (MB) and sacrificed. (B-D) Representative double-plotted actograms of a birds from each state viz (B) NMB, (C) PMB and (D) MB phases. Activity counts during (E) daytime, (F) nighttime, (G) total activity/day, and (H) per hour. The changes in (I) body mass, $(\mathbf{J})$ fat score, $(\mathbf{K})$ testis volume, and $(\mathbf{L})$ food intake of birds during NMB, PMB and MB phases. $* P<0.05$ compared to NMB and PMB in $\mathbf{G}, \mathbf{J}, \mathbf{K}$ and PMB in $\mathbf{L}$; $* * P<0.01$ compared to NMB and PMB in $\mathbf{F}$ and NMB in $\mathbf{L} ; n s$, non-significant

3 = fat deposits overlie entire region, $4=$ area filled with whitish, bulging fat deposits, and $5=$ copious fat deposits over furcula, scapula and abdominal area) (Malik et al. 2004; Budki et al. 2009). The size of testis was recorded as volume of the left testis measured with reference to an accurate scale on a graph sheet, after birds were perfused at the end of the experiment. Using formula $4 / 3 \pi \mathrm{ab}^{2}$ [ $\mathrm{a}$ and $\mathrm{b}=$ half of the long (length) and short (width) axes, respectively], the testis volume was calculated as measure of change in the dimension of the testes.

\section{Tissue processing for immunofluorescence}

Buntings were anaesthetized using a mixture of ketamine and xylazine (ketamine: $40 \mathrm{mg} / \mathrm{kg}$ and xylazine: $10 \mathrm{mg} /$ $\mathrm{kg}$ body weight) and perfused transcardially with $100 \mathrm{ml}$ phosphate-buffered saline (PBS; pH 7.4) and $80 \mathrm{ml}$ of $4 \%$ formaldehyde in $0.1 \mathrm{M}$ phosphate buffer. Brains were dissected out from each bird and post-fixed in $4 \%$ formaldehyde for $24 \mathrm{~h}$. Similarly, the rats were anaesthetized and perfused and brain dissected out and post-fixed. For the cryoprotection, tissues were then immersed in $25 \%$ sucrose solution in PBS overnight at $4{ }^{\circ} \mathrm{C}$. The brains were rapidly frozen in dry ice, embedded in tissue mounting medium and $30 \mu \mathrm{m}$ thick coronal sections through the rostro-caudal extent of the brain were cut on a cryostat (CM3050 S; Leica, Germany). The sections were collected in PBS to obtain four sets of free-floating sections.

\section{Hypothalamic distribution and putative regulatory role of CART}

To study distribution and evaluate the role of CART immunoreactivity in the POA and hypothalamus, one set of brain sections from each bird in all groups were processed for the immunofluorescence as described by (Singh et al. 2016a). The sections were rinsed in the PBS, immersed in $0.5 \%$
Triton X-100 in PBS for 30 min followed by 5\% normal horse serum in PBS for $30 \mathrm{~min}$. They were incubated in diluted rabbit polyclonal anti-CART antiserum (Table 1) for $24 \mathrm{~h}$ at $4{ }^{\circ} \mathrm{C}$. Few sections containing suprachiasmatic nucleus ( $\mathrm{SCN}$ ) were incubated in rabbit polyclonal anti-vasoactive intestinal peptide antiserum (VIP, Table 1). After rinsing in PBS, the sections were incubated in AlexaFluor488conjugated goat anti-rabbit IgG (Invitrogen; dilution 1:500) for $4 \mathrm{~h}$ at the room temperature. They were washed in PBS followed by TRIS buffer, mounted on the glass slide and coverslipped with Vectashield mounting medium containing DAPI (Vector). The sections were observed under the AxioImager M2 fluorescence microscope (Carl Zeiss, Germany), and photomicrographs were captured with AxioCam camera attached to the microscope equipped with Zen2011 software (Carl Zeiss, Göttingen, Germany). The photomicrographs were adjusted for size, brightness and contrast using Adobe Photoshop CS4 and panels were prepared.

To identify different POA and hypothalamic nuclei, sections were processed for cresyl-violet staining. The sections were mounted on the slides, stained with $1 \%$ cresyl violet and differentiated in acetic acid in ethanol. After dehydration in the ascending series of ethanol, the sections were immersed in xylene and coverslipped with DPX mounting medium. The schematics of coronal section containing the POA and hypothalamic regions of buntings were prepared using CorelDraw software, as in previous studies (Rastogi et al. 2011; Singh et al. 2013). The terminology and identification of regions/nuclei in the POA and hypothalamus of redheaded bunting was adopted from previous studies (Kuenzel and van Tienhoven 1982; Meddle and Follett 1997; Cardot et al. 1999; Brandstätterr and Abraham 2003; Rastogi et al. 2013; Singh et al. 2016a).

\section{Double immunofluorescence}

We performed double immunofluorescence histochemistry to characterize the CART-immunoreactive neurons in the POA and hypothalamic nuclei of the redheaded bunting, using CART antiserum and antisera for each neurotransmitter/neuropeptide (Table 1). Both avian POA and hypothalamus have been shown containing TH (a marker enzyme of dopamine biosynthesis; Bottjer 1993; Kabelik et al. 2011), NPY and POMC (Boswell 2005; Boswell and Dunn 2017), and mesotocin (Bons 1980; Chokchaloemwong et al. 2013; Hall et al. 2015) neurons; NPY fibers densely innervate DMN of the redheaded buntings (Rastogi et al. 2013). Specifically, hypothalamic sections containing the lateral hypothalamic nucleus (LHN), paraventricular nucleus (PVN), ventral supraoptic nucleus (SOv), nucleus dorsomedialis hypothalami (DMN), inferior hypothalamic nucleus (IH) and hypothalamic infundibular nucleus (IN), and median preoptic nucleus (PONm) were processed for 
Table 1 Details of the primary antibodies used

\begin{tabular}{|c|c|c|c|c|c|}
\hline Antigen & Host & Antibody type & Immunogen & $\begin{array}{l}\text { Source/catalogue number/ } \\
\text { research resource identifiers } \\
\text { (RRIDs) }\end{array}$ & Dilution \\
\hline $\begin{array}{l}\text { Cocaine- and amphetamine- } \\
\text { regulated transcript } \\
(\text { CART })\end{array}$ & Rabbit & Polyclonal & $\begin{array}{l}\text { CART (55-102): Ile-Pro-Ile- } \\
\text { Tyr-Glu-Lys-Lys-Tyr-Gly- } \\
\text { Gln- Val-Pro-Met-Cys- } \\
\text { Asp-Ala- Gly-Glu-Gln- } \\
\text { Cys-Ala-Val-Arg-Lys-Gly- } \\
\text { Ala-Arg-Ile-Gly-Lys-Leu- } \\
\text { Cys-Asp-Cys-Pro-Arg- } \\
\text { Gly-Thr-Ser-Cys-Asn-Ser- } \\
\text { Phe-Leu-Leu-Lys-Cys-Leu } \\
\text { [Disulfide bonds between } \\
\text { Cys 1-Cys 3, Cys 2-Cys 5, } \\
\text { Cys 4-Cys 6] }\end{array}$ & $\begin{array}{l}\text { Phoenix Pharmaceuticals } \\
\text { Inc., Cat. \# H-003-62 } \\
\text { RRID: AB_2313614 }\end{array}$ & $1: 5000$ \\
\hline $\begin{array}{l}\text { Vasoactive intestinal peptide } \\
\text { (VIP) }\end{array}$ & Rabbit & Polyclonal & $\begin{array}{l}\text { Full length protein VIP } \\
\text { (Pig) conjugated to bovine } \\
\text { thyroglobulin by a CDI } \\
\text { linker }\end{array}$ & $\begin{array}{l}\text { Abcam, Cat. \# ab43841 } \\
\text { RRID: AB_778831 }\end{array}$ & $1: 2000$ \\
\hline $\begin{array}{l}\text { Alpha-melanocyte-stimulat- } \\
\text { ing hormone }(\alpha-\mathrm{MSH})\end{array}$ & Sheep & Polyclonal & $\begin{array}{l}\text { MSH conjugated with } \\
\text { bovine thyroglobulin }\end{array}$ & $\begin{array}{l}\text { Kind gift of Professor Jef- } \\
\text { frey Tatro, Tufts Medi- } \\
\text { cal Center, Boston, MA } \\
\text { RRID: AB_91683 }\end{array}$ & $1: 5000$ \\
\hline Neuropeptide Y (NPY) & Sheep & Polyclonal & $\begin{array}{l}\text { Synthetic NPY peptide } \\
\text { conjugated to bovine } \\
\text { thyroglobulin }\end{array}$ & $\begin{array}{l}\text { Millipore, Cat. \# AB1583 } \\
\text { RRID: AB_2236176 }\end{array}$ & $1: 5000$ \\
\hline NPY & Rabbit & Polyclonal & $\begin{array}{l}\text { Synthetic NPY (porcine) } \\
\text { conjugated to KLH }\end{array}$ & $\begin{array}{l}\text { Sigma, Cat. \# N9528 RRID: } \\
\text { AB_260814 }\end{array}$ & $1: 5000$ \\
\hline Oxytocin & Mouse & Monoclonal & $\begin{array}{l}\text { Oxytocin conjugated to } \\
\text { thyroglobulin }\end{array}$ & $\begin{array}{l}\text { Millipore, Cat. \# MAB5296 } \\
\text { RRID: AB_2157626 }\end{array}$ & $1: 2000$ \\
\hline Oxytocin & Rabbit & Polyclonal & $\begin{array}{l}\text { Synthetic oxytocin conju- } \\
\text { gated to thyroglobulin }\end{array}$ & $\begin{array}{l}\text { Millipore, Cat. \# AB911 } \\
\text { RRID: AB_2157629 }\end{array}$ & $1: 2000$ \\
\hline Tyrosine hydroxylase $(\mathrm{TH})$ & Mouse & Monoclonal & TH purified from $\mathrm{PC} 12$ cells & $\begin{array}{l}\text { Millipore, Cat. \# MAB318 } \\
\text { RRID: AB_2201528 }\end{array}$ & $\begin{array}{l}\text { Immunofluorescence: } \\
\text { 1:1000; Western blot } \\
\text { analysis: } 1: 1500\end{array}$ \\
\hline TH & Sheep & Polyclonal & $\begin{array}{l}\text { Native tyrosine hydroxylase } \\
\text { from rat pheochromocy- } \\
\text { toma }\end{array}$ & $\begin{array}{l}\text { Millipore, Cat. \# MAB1542 } \\
\text { RRID: AB_90755 }\end{array}$ & $1: 1000$ \\
\hline
\end{tabular}

double immunofluorescence, as described earlier (Singh et al. 2016a, b). The sections were prepared as described above in Sect. "Hypothalamic distribution and putative regulatory role of CART", and incubated in a mixture of diluted (i) mouse monoclonal anti-TH antibodies and rabbit polyclonal anti-CART antiserum for PONm and LHN, (ii) mouse monoclonal anti-oxytocin antibodies and rabbit polyclonal anti-CART antiserum for PVN and SOv, (iii) sheep polyclonal anti-NPY and rabbit polyclonal anti-CART antisera for DMN, IH and IN, or (iv) sheep polyclonal anti- $\alpha-M S H$ and rabbit polyclonal anti-CART antisera for IH and IN. The sections were incubated in antisera mixture for $24 \mathrm{~h}$ at $4{ }^{\circ} \mathrm{C}$, rinsed in PBS and re-incubated in a mixture of either AlexaFluor594-conjugated anti-mouse or anti-sheep IgG and AlexaFluor488-conjugated anti-rabbit IgG (Invitrogen, 1:500) for $4 \mathrm{~h}$ at the room temperature. PBS-rinsed sections were mounted on glass slides, and coverslipped with
Vectashield mounting medium. The sections were observed under an AxioImager fluorescence microscope, analysed, and photomicrographs captured as described above in Sect. "Hypothalamic distribution and putative regulatory role of CART".

\section{Specificity of antisera}

The details of the antisera used in the study are given in Table 1. The specificity of rabbit polyclonal anti-CART antiserum used in the present study has been well established in the brain of other bird (Singh et al. 2016a). In the western blot analysis, application of the anti-CART antiserum showed multiple bands of CART propeptide fragments in the brain of zebra finch (Singh et al. 2016a). To determine the specificity of the anti-CART antiserum in the brain of redheaded bunting, hypothalamic sections containing PVN 
and IN were incubated in the rabbit polyclonal anti-CART antiserum preadsorbed with the synthetic CART peptide at $10^{-5} \mathrm{M}$ concentration followed by incubation in AlexaFluor488-conjugated anti-rabbit IgG. The sections were rinsed in PBS, mounted on the glass slides, coverslipped with Vectashield mounting medium, and observed under fluorescence microscope. The anti-VIP antiserum has been raised against full length VIP (pig) conjugated with bovine thyroglobulin by a CDI linker. The specificity of the antiserum in the brain of Emberiza melanocephala (an allied migrant species) has been validated using different controls (Rastogi et al. 2013). The specificity of anti-VIP and NPY antisera in the brain of birds including black-headed bunting has already been established (Rastogi et al. 2013; Surbhi et al. 2015). To establish the specificity for redheaded bunting, while the hypothalamic sections were incubated for $24 \mathrm{~h}$ with anti-VIP, NPY, and $\alpha$-MSH antisera preadsorbed with their respective control peptides at $10^{-5} \mathrm{M}$ concentration, the anti-oxytocin antibodies were preadsorbed with mesotocin peptide. In addition to the mouse monoclonal anti-oxytocin antibodies, sections were also incubated in rabbit polyclonal anti-oxytocin antiserum to compare the pattern of immunoreactivity in the PVN of birds. Similarly, the rabbit polyclonal anti-NPY antiserum was employed to compare the pattern of NPY immunoreactivity in the DMN with sheep anti-NPY antiserum. The antiserum we used for TH has been used for the localization of dopaminergic systems in the brain of birds (Kabelik et al. 2011; Sen et al. 2019); it labels distinct TH-immunoreactive neurons in the POA and LHN (Bottjer 1993; Kabelik et al. 2011). Following incubation, the sections were processed for immunofluorescence using AlexaFluor488-conjugated secondary antibodies (anti-rabbit IgG for rabbit anti-VIP, NPY and oxytocin; anti-mouse IgG for mouse anti-TH antibodies; and anti-sheep IgG for sheep anti- $\alpha$-MSH and NPY antisera). The sections were rinsed in PBS, mounted on glass slides, coverslipped with Vectashield mounting medium, observed under an AxioImager fluorescence microscope, and images captured as described above.

For determining the specificity of the $\mathrm{TH}$ antibodies in the brain of redheaded bunting, hypothalamic sections were incubated in either mouse monoclonal anti-TH antibodies, sheep polyclonal anti-TH antiserum, or normal serum in place of the primary $\mathrm{TH}$ antiserum, and processed for immunofluorescence. The sections were incubated in the fluorescence conjugated secondary antibodies (AlexaFluor488conjugated anti-mouse or anti-sheep $\operatorname{IgG}$ ) as described above. The sections were rinsed in PBS, mounted on glass slides and coverslipped with mounting medium. The sections were observed under a fluorescence microscope and photomicrographs captured as described above. In the midbrain of mammals, the mouse anti-TH antibody recognizes the dopaminergic neurons in the ventral tegmental area/substantia nigra (Gombash et al. 2014; Ho et al. 2015). The rat midbrain sections containing the ventral tegmental area/substantia nigra were incubated in mouse anti-TH antiserum followed by Alexa-Fluor-594-conjugated anti-mouse IgG. To further establish the specificity of the mouse anti-TH antibodies in the brain of redheaded bunting, western blot analysis of the hypothalamic tissue was performed, as described previously (Singh et al. 2019). Birds were anaesthetised as described above. The brains removed, frozen on dry ice, and hypothalamic tissue block was cut. The tissue was homogenised in RIPA buffer [ $50 \mathrm{mM}$ sodium phosphate buffer, $\mathrm{pH} 7.4,500 \mathrm{mM}$ sodium chloride, $1 \%$ Triton X-100, 0.05\% sodium deoxycholate, $0.1 \%$ sodium dodecyl sulphate (SDS), $0.5 \mathrm{mM}$ ethylenediaminetetraacetic acid, $0.5 \mathrm{mM}$ ethylene glycol tetraacetic acid, 9.9\% glycerol] containing phenylmethylsulphonyl fluoride $(1 \mathrm{mM})$ in ethanol, and protease inhibitor cocktail (1\% in sodium phosphate buffer, Sigma). After centrifugation, the supernatant obtained. The protein sample was then run on Tris/glycine SDS-polyacrylamide (10\%) gel electrophoresis, using a mini-gel apparatus (BioRad, Hercules, CA, USA) along with a PageRuler ${ }^{\mathrm{TM}}$ Plus prestained protein ladder (Cat. \# 26,619, ThermoScientific). Using immunoblotting with mini-gel electrotransfer system (Bio-Rad), the proteins were transferred to the polyvinylidene difluoride membranes (Immobilon-P, Sigma) in the running buffer ( $25 \mathrm{mM}$ Tris base, $190 \mathrm{mM}$ glycine, $0.1 \%$ $\mathrm{SDS}, \mathrm{pH} \mathrm{8.3)}$ for $1 \mathrm{~h}$ at $17 \mathrm{~V}$. The membrane was rinsed in $5 \%$ bovine serum albumin (HIMEDIA, India) for $1 \mathrm{~h}$ and incubated overnight at room temperature in either the diluted mouse anti-TH antibodies (1:1500) or blocking solution with no primary antibody. Following rinsing in Tris-buffered saline Tween 20 buffer (pH 7.6), membrane incubated for $1 \mathrm{~h}$ at room temperature in goat anti-mouse horseradish peroxidase-conjugated antibodies (dilution 1:5000; Cell Signaling Technology, USA). The membrane was rinsed in buffer and the immunoreactive proteins detected using enhanced chemiluminescence (ECL, Amersham, UK) in FluorChem E system (ProteinSimple, CA, USA) and image captured.

\section{The image analysis}

As previously described (Gutekunst et al. 2010; Singh et al. 2016a), the number and density of CART-immunoreactive cells and fibers in the rostro-caudal series of sections through the POA and hypothalamic areas were analyzed using a qualitative scale (-, negative; + , occasional/isolated; ++ , few; +++ , several; Table 2 ). Using computerized image analysis, the percent fluorescent area and number of CART-immunoreactive cells in the PONm, SCN, SOv, anterior hypothalamic nucleus (AN), LHN, PVN, DMN, $\mathrm{IH}$, and IN were determined, as previously described (Singh et al. 2016a,2019). Briefly, we selected five hypothalamic sections encompassing rostro-caudal extent of each nucleus on either side of the brain. Photomicrographs of these nuclei 
Table 2 CART-immunoreactive cells and fibers in the preoptic area/ hypothalamus of E. bruniceps

\begin{tabular}{lll}
\hline Regions of the poa/hypothalamus & CELLS & $\begin{array}{l}\text { FIBERS/ } \\
\text { TERMI- } \\
\text { NALS }\end{array}$ \\
\hline Preoptic nucleus (PON) & & \\
Anterior preoptic nucleus (PONa) & + & ++ \\
Medial preoptic nucleus (PONm) & ++ & ++ \\
Periventricular preoptic nucleus (PPN) & - & ++ \\
Suprachiasmatic nucleus (SCN) & & \\
SCN, medial (SCNm) & ++ & ++ \\
SCN, visual (SCNv) & + & ++ \\
Supraopticus nucleus, ventral (SOv) & ++ & ++ \\
Anterior hypothalamic nucleus (AN) & ++ & +++ \\
Paraventricular nucleus (PVN) & +++ & +++ \\
Nucleus dorsomedialis hypothalami (DMN) & ++ & ++ \\
Nucleus ventromedialis hypothalamic (VMN) & - & ++ \\
Lateral hypothalamic nucleus (LHN) & +++ & +++ \\
Inferior hypothalamic nucleus (IH) & ++ & +++ \\
Hypothalamic infundibular nucleus (IN) & + & +++ \\
Median eminence & - & +++ \\
\hline
\end{tabular}

- negative, + , isolated/occasional +++ , few $;+++$ several

were captured using a CCD camera attached to the fluorescence microscope and the images were digitized. Using Image J software (National Institute of Health, USA), images were set at threshold which included the immunoreactivity and subtracting the background, and the region of interest selected using the drawing tool in the software. The percent fluorescent area of CART immunoreactivity in different hypothalamic nuclei was calculated by an automatic quantification. Hypothalamic sections from each individual bird from different groups were processed together to minimize the error during immunofluorescence staining. The microscope settings including the objective, exposure time, and fluorescence intensity remained the same during the entire analysis. The number of CART-immunoreactive cells in the hypothalamic nuclei in all three photoinduced seasonal states were counted and the cell numbers were corrected using Abercrombie's method (Abercrombie 1946). Data from all birds in a group were pooled, averaged and the mean \pm SEM was calculated. The analyses were performed double blind; each slide was coded and analyzed by a person blind to the experiment.

The percentage of CART-immunoreactive neurons coexpressing (i) mesotocin in the PVN and SOv, and (ii) NPY or $\alpha-\mathrm{MSH}$ in the IH and IN, in the hypothalamus of the bunting were analysed as described earlier by Singh et al. (2016a). Five double-labelled sections containing the PVN, $\mathrm{SOv}$, IH and IN from each bird were analyzed under a fluorescence microscope. The filter sets (green for CART and red for mesotocin, NPY or $\alpha-M S H)$ were switched, and the number of double-labeled neurons was counted on either side of the hypothalamus from each bird, and percentage was determined. The data obtained from sections from each animal were pooled and the mean \pm SEM calculated.

\section{Statistical analysis}

All statistical analyses were performed using GraphPad Prism software (GraphPad Software Inc, USA). Data were analyzed by One-way analysis of variance (one-way ANOVA) followed by Newman-Keuls multiple comparison test, if ANOVA indicated a significant difference. However, data on fat score were analyzed using the Kruskal-Wallis nonparametric test followed by Dunn's multiple comparison post-test. $P<0.05$ was considered statistically significant.

\section{Results \\ Photoperiod-induced changes in behavioural and physiological phenotype}

As expected of a diurnal species, buntings were active during the day in both SD-induced (group I) and LD-induced PMB (group II) states (Fig. 1B, C). However, with the subsequent LD-induced photostimulation of MB state (migratory phenotype; group III, Fig. 1D), birds developed an intense night-time activity, a feature in captive condition when a migrant is disallowed from migrating (called migratory nocturnal restlessness, Zugunruhe, comparable to that of the onset of migratory night flight in the wild). Thus, there was significantly higher night activity (NMB or PMB; $F_{2,12}=10.21 ; P=0.0026$; one-way ANOVA; Fig. 1B-D, F), total $24 \mathrm{~h}$ activity (NMB or PMB; $F_{2,12}=4.923 ; P=0.0275$; one-way ANOVA; Fig. 1B-D, G), and activity of bird per hour (NMB or PMB; $F_{2,12}=5.113 ; P=0.0085$; one-way ANOVA; Fig. 1B-D, H) in MB as compared to the other seasonal states without affecting the total daytime activity (Fig. 1B-E).

Apart from effects on diurnal activity behavior, we found a significant difference in food intake between photoinduced seasonal states $\left(F_{2,12}=9.224 ; P=0.0037\right.$; one-way ANOVA; Fig. 1L). Compared to NMB, birds showed hyperphagia and consumed significantly more food in the PMB state $(P<0.01$; Fig. 1L). While the food intake of birds was significantly reduced in subsequent $\mathrm{MB}$ state, as compared to the PMB state $(P<0.05$; Fig. $1 \mathrm{~L})$, we found significant difference in the fat score $(P=0.0108$; NMB vs. MB, $P<0.05$; Fig. $1 \mathrm{~J}$ ), but not in the body mass of birds between three seasonal states, NMB, PMB, and MB states (Fig. 1I). On the other hand, LD birds showed testicular recrudescence, with the overall significant difference in testis size between three photoinduced seasonal states $\left(F_{2,12}=4.248 ; P=0.0403\right.$; 
one-way ANOVA; Fig. $1 \mathrm{~K}$; NMB vs. $\mathrm{MB}, \mathrm{TV}=P<0.05$; Fig. 1K).

\section{Organization of CART immunoreactivity in the hypothalamus of redheaded bunting}

Figure 2 shows the specificity of rabbit polyclonal antiCART and anti-VIP antisera, sheep polyclonal anti-NPY, and $\alpha$-MSH antisera, and anti-oxytocin antibodies in the hypothalamus of redheaded buntings. The application of CART antiserum on the hypothalamic sections resulted in labeling of cells and fibers in the hypothalamic nuclei including PVN (Fig. 2A) and IN (Fig. 2B). CART immunoreactivity was absent in PVN (Fig. 2G), IN (Fig. 2H), POA and other hypothalamic regions when the brain sections were incubated in preadsorbed anti-CART antiserum.

The application of anti-VIP, anti-NPY, and anti- $\alpha$-MSH antisera, and anti-oxytocin antibodies on the hypothalamic sections of redheaded bunting, resulted in the cells/fibers labelling of different hypothalamic nuclei [VIP-immunorreactivity in SCNm (Fig. 2C), NPY-immunoreactivity in IN (Fig. 2D), $\alpha$-MSH-immunoreactivity in IN (Fig. 2E), oxytocin-immunorecativity in PVN (Fig. 2F)]. The preadsorption of anti-VIP, $\alpha-\mathrm{MSH}$, and NPY antisera with respective control peptides, and of oxytocin antibodies with mesotocin peptide did not show any immunoreactivity in different hypothalamic regions, namely VIP-immunoreactivity in SCNm (Fig. 2I), NPY-immunoreactivity in IN (Fig. 2J), $\alpha$-MSH-immunoreactivity in IN (Fig. 2K) and mesotocin-immunoreactivity in PVN (Fig. 2L)]. Application of mouse monoclonal anti-oxytocin antibodies or rabbit polyclonal anti-oxytocin antibodies showed comparable immunostaining pattern in the PVN of buntings. The rabbit and sheep anti-NPY antisera showed comparable pattern of immunoreactivity in the DMN, IN, and IH. The application of mouse monoclonal anti-TH antibodies resulted in the labelling of TH-immunoreactive neurons and fibers in the POA and LHN. In the midbrain of rat, the application of this antibody labelled the neurons and fibers in the ventral tegmental area and substantia nigra (Fig. 3A), serving as positive control. The pattern of TH-immunoreactivity in the midbrain of rat was comparable to that previously described (Gombash et al. 2014; Ho et al. 2015). Application of sheep polyclonal anti-TH antiserum or mouse anti-TH antibodies on the hypothalamic sections of redheaded bunting resulted in a comparable pattern of labelling of TH-immunoreactive cells/fibers (Fig. 3B). Replacement of the anti-TH antibodies from immunofluorescence did not show any immunoreactivity signal in the hypothalamic regions (Fig. 3C). Further, in the western blot analysis of the hypothalamic extract of redheaded bunting, while the application of mouse anti$\mathrm{TH}$ antibodies detected a single $\mathrm{TH}$-immunoreactive band of $\sim 64 \mathrm{kDa}$, corresponding to the molecular weight of $\mathrm{TH}$,
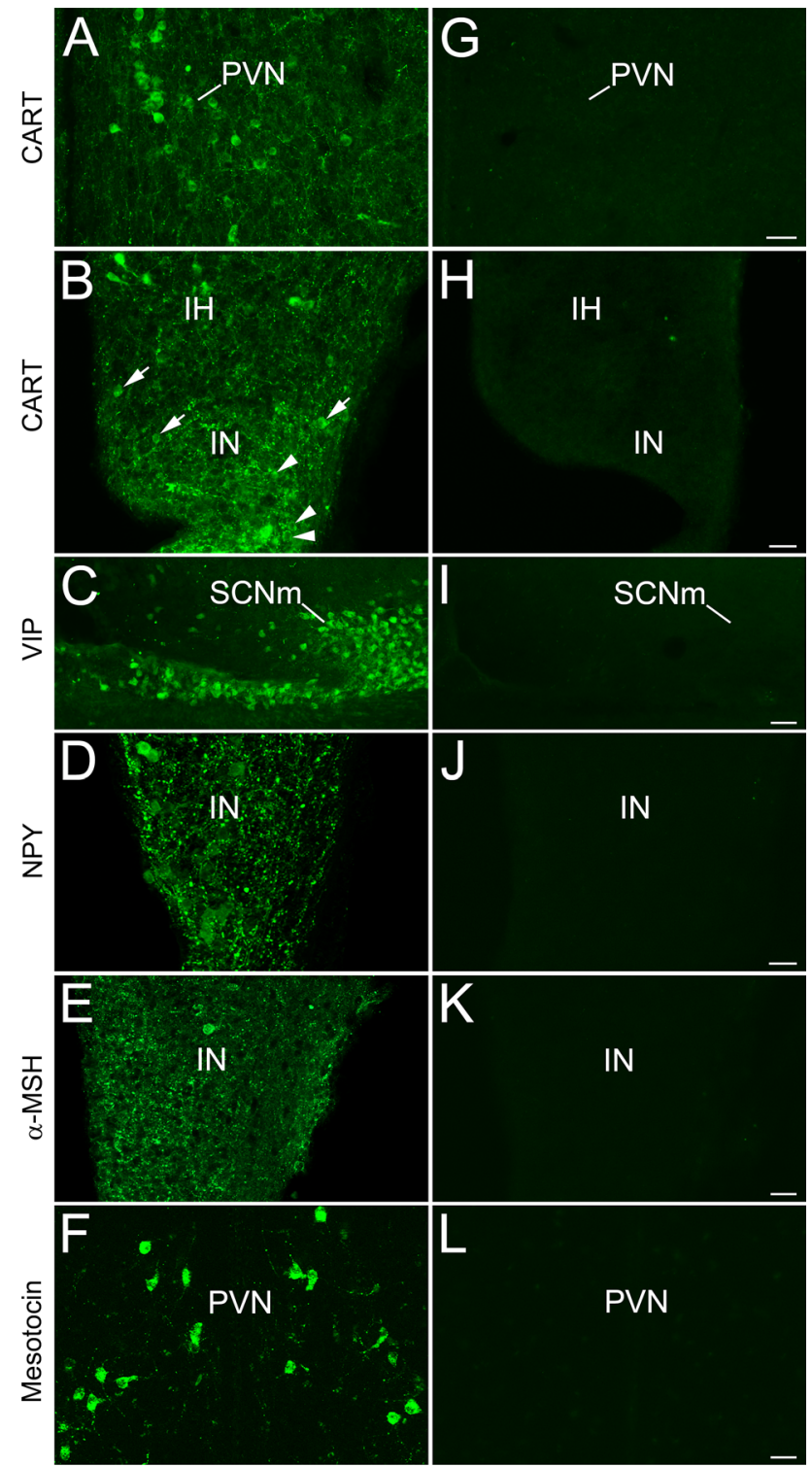

Figure 2

Fig. 2 Fluorescence photomicrographs showing specificity of the rabbit polyclonal anti-CART $(\mathbf{A}, \mathbf{B}, \mathbf{G}, \mathbf{H})$ and anti-VIP $(\mathbf{C}, \mathbf{I})$ antisera, sheep polyclonal anti-NPY $(\mathbf{D}, \mathbf{J})$ and anti- $\alpha$-MSH $(\mathbf{E}, \mathbf{K})$ antisera, and mouse monoclonal anti-oxytocin antibodies $(\mathbf{F}, \mathbf{L})$ in the hypothalamus of E. bruniceps. CARTimmunoreactive neurons and fibers are seen in the hypothalamic paraventricular (PVN, A) and infundibular (IN, B) nuclei. Intensely (arrows) and weakly labelled (arrowheads) CART cells/fibers in IN (B). No CART immunoreactivity is seen in the PVN (G) and IN (H) following incubation of the hypothalamic sections with anti-CART antiserum preadsorbed with control peptide. VIP-immunoreactive cells/fibers are seen in the medial suprachiasmatic nucleus ( $\mathrm{SCNm}, \mathrm{C}$ ). No VIP immunoreactivity is seen in the SCNm when the control peptide preadsorbed VIP antiserum was applied on the hypothalamic sections (I). In IN, application of anti-NPY antiserum labeled cells and fibers (D) but no immunoreactivity is seen following incubation of the hypothalamic sections with anti-NPY antiserum preadsorbed with control peptide (J). The $\alpha$-MSH-immunoreactive neurons/fibers are seen in the IN (E). Complete loss of $\alpha$-MSH-immunoreactivity is seen in the IN following application of the control peptide preadsorbed $\alpha$-MSH antiserum on hypothalamic sections (K). Mesotocin-immunoreactive neurons/fibers are seen in the PVN (F) and this immunoreactivity is abolished when the hypothalamic sections were incubated in oxytocin antibodies preadsorbed with mesotocin peptide $(\mathbf{L})$. IH, inferior hypothalamic nucleus; $v$ ventricle. Scale bar $=25 \mu \mathrm{m}$ 

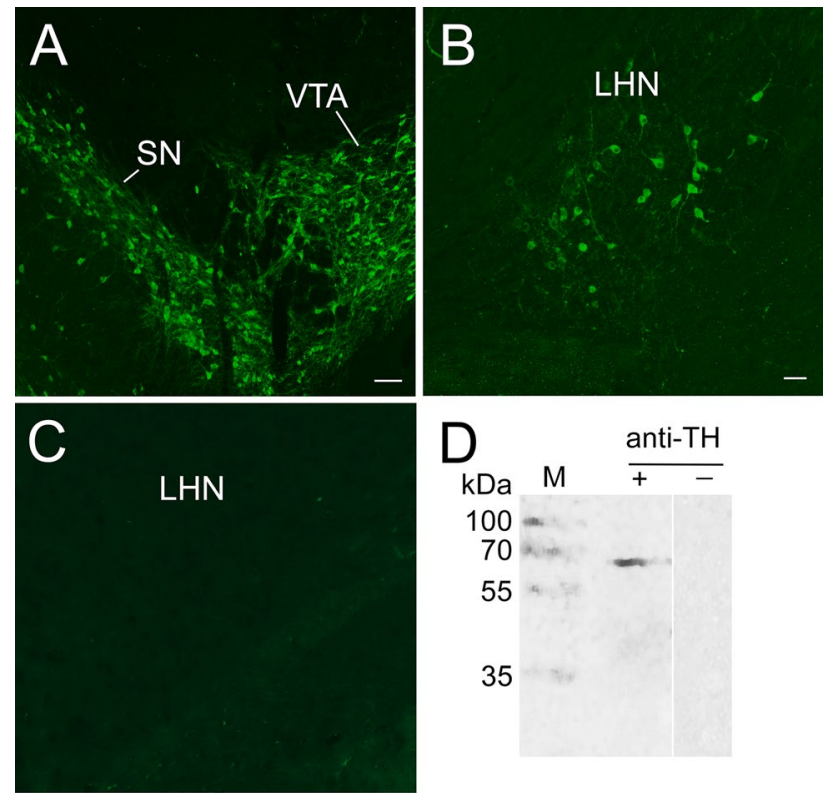

Fig. 3 Fluorescence photomicrographs $(\mathbf{A}-\mathbf{C})$ and western blot analysis (D) showing specificity of the anti-TH antibodies. TH-immunoreactive cells/fibers are seen in the substantia nigra $(\mathrm{SN})$ and ventral tegmental area (VTA) in the midbrain of rat using mouse monoclonal anti-TH antibodies (A). In the hypothalamus of E. bruniceps, $\mathrm{TH}$-immunoreactive cells/fibers are seen in the lateral hypothalamic nucleus (LHN) following the application of sheep polyclonal anti$\mathrm{TH}$ antiserum (B). No immunoreactivity is seen in the hypothalamic sections of $E$. bruniceps incubated in normal serum without the anti$\mathrm{TH}$ antibody (C). Distinct TH-immunoreactive band of $\sim 64 \mathrm{kDa}$ in the hypothalamic extract of E. bruniceps following the application of mouse anti-TH antibodies (D). No TH-immunoreactive band is observed following replacement of the anti-TH antibodies with blocking solution. $M$, molecular weight marker; + , with anti-TH antibodies; - , without primary anti-TH antibodies. Scale bar $=50 \mu \mathrm{m}$ in $\mathbf{A}$ and $25 \mu \mathrm{m}$ in $\mathbf{B}, \mathbf{C}$

replacement of the anti-TH antibodies with blocking solution did not show any signal (Fig. 3D).

Figure 4 represents the neuroanatomical organization of different nuclei in the POA and hypothalamus of the redheaded bunting, and the presence of CART-immunoreactive cells and fibers in these regions. Figures 5, 6 and Table 2 show CART-immunoreactive cells and fibers in the POA and other hypothalamic regions. We found distinct CARTimmunoreactive neurons and fibers in the POA (Figs. 4E, 5A-D), which as shown by Nissl staining had three subdivisions, namely the anterior (PONa), medial (PONm), and periventricular (PPN) preoptic nuclei (Figs. 4A, 10A-C). Both CART-immunoreactive cells and fibers were observed in PONa and PONm, cells in PONa were larger than PONm; no CART-immunoreactive cells but CART-immunoreactive fibers were seen in the PPN (Figs. 4E, 5A-D). The hypothalamic SCN of redheaded buntings consists of the medial $(\mathrm{SCNm})$ and ventral $(\mathrm{SCNv})$ subdivisions. Distinct moderately labelled CART-immunoreactive neurons and fibers

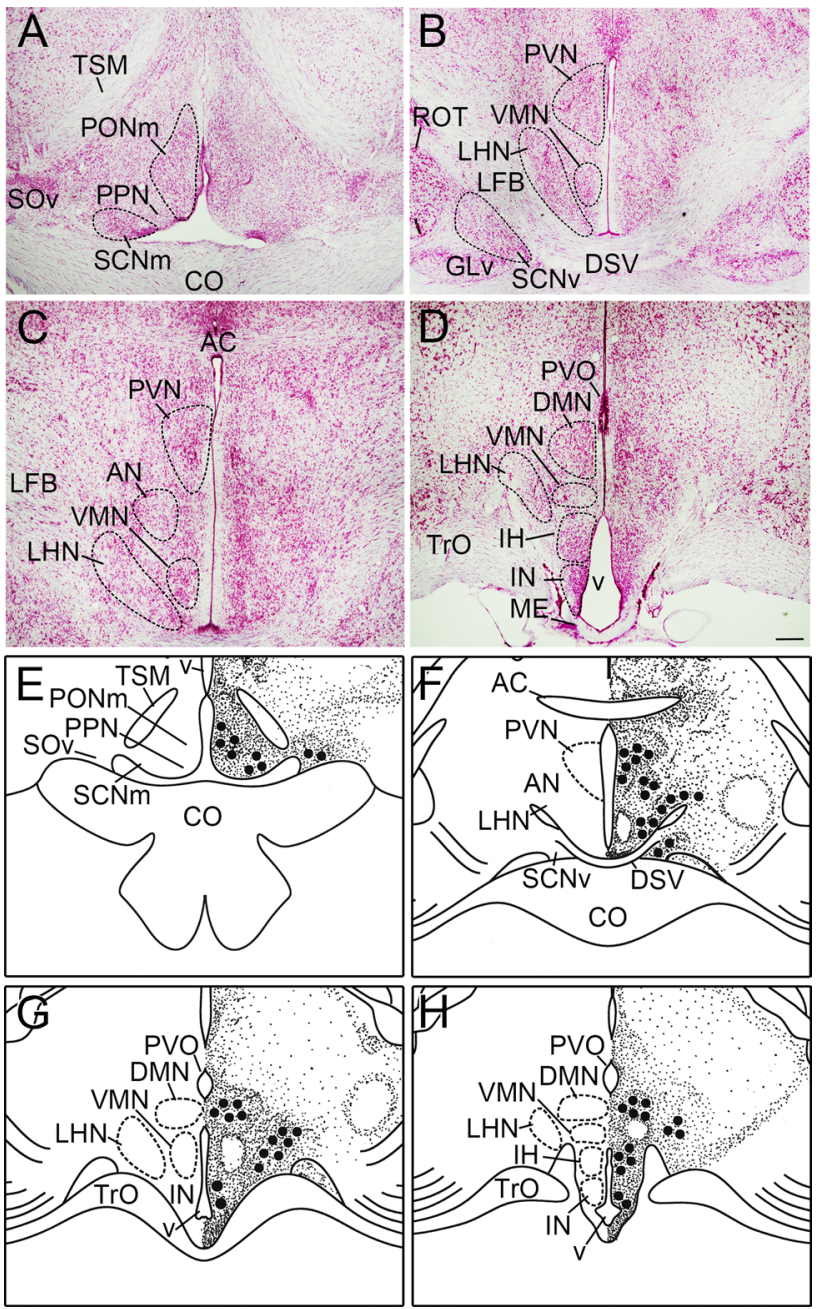

Fig. 4 Nissl stained photomicrographs (A-D) and schematics (E-H) of the transverse sections through the rostro-caudal extent of the preoptic area and hypothalamus of E. bruniceps showing neuroanatomical organization (A-D) and the organization of CART-immunoreactive neurons (filled circles) and fibers (dots and dashed lines) (E-H). For the details of the nuclei and brain regions, please see abbreviations. Scale bar $=100 \mu \mathrm{m}$ in $\mathbf{A}-\mathbf{D}$

were found in both subdivisions [(SCNm, Figs. 4E, 5A, A1, E, F) and (SCNv, Fig. 4F)]. While the application of antiVIP antiserum labelled several SCN neurons (Fig. 5G), the CART-immunoreactive cells/fibers were observed in the SOv (Figs. 4E; 5H, H1), AN (Figs. 4F; 6A, E, I), LHN (Figs. 4F-H; 6A, J), PVN (Figs. 4F; 6A, C, K), and DMN (Figs. 4G, H; 6B, D, L). Similarly, in the mediobasal hypothalamus (MBH), CART-immunoreactive cells and fibers were observed in the IH (Figs. 4H; 6F, M) and IN (Figs. 4G, $\mathrm{H} ; 6 \mathrm{~B}, \mathrm{G}, \mathrm{N})$. CART-immunoreactive fibers were also found in the external zone of the median eminence (Fig. 6H).

The application of anti-NPY, $\alpha-\mathrm{MSH}$, oxytocin, and TH antisera resulted in the labelling of cells/fibers in distinct hypothalamic nuclei of redheaded buntings. While both 
Fig. 5 Fluorescence photomicrographs showing CARTimmunoreactive cells and fibers in the preoptic area (POA), and suprachiasmatic (SCN) and ventral supraoptic (SOv) nuclei of E. bruniceps. Low magnification photomicrograph showing CART-immunoreactive cells and fibers in the medial $(\mathrm{PONm})$ and periventricular $(\mathrm{PPN})$ preoptic nuclei in POA, and median $\mathrm{SCN}$ (SCNm) (A). The magnified view of cells in $\mathrm{SCNm}$ is shown in inset (A1). CART-immunoreactive cells/ fibers in the anterior preoptic nucleus (PONa) (B), PPN (C), $\mathrm{PONm}(\mathbf{D})$, and $\mathrm{SCNm}(\mathbf{E}, \mathbf{F})$. Low- (E) and high (F)-magnification photomicrographs of SCNm. Strong (arrows) and weak (arrowheads) CARTimmunoreactive cells in $\mathrm{SCNm}$ (F). The neuroanatomical location of SCN was identified by the presence of vasoactive intestinal peptide (VIP)-immunoreactive cells (G). CARTimmunoreactive cells and fibers are also seen in SOv $(\mathbf{H})$. High magnification photomicrograph of cells in SOv (H1). CO optic chiasma; $v$ ventricle. Scale bar $=50 \mu \mathrm{m}$ in $\mathbf{A}, \mathbf{G} ; 25 \mu \mathrm{m}$ in $\mathbf{B}-\mathbf{E}, \mathbf{H}, \mathrm{A} 1$; and $5 \mu \mathrm{m}$ in $\mathbf{F}, \mathrm{H} 1$
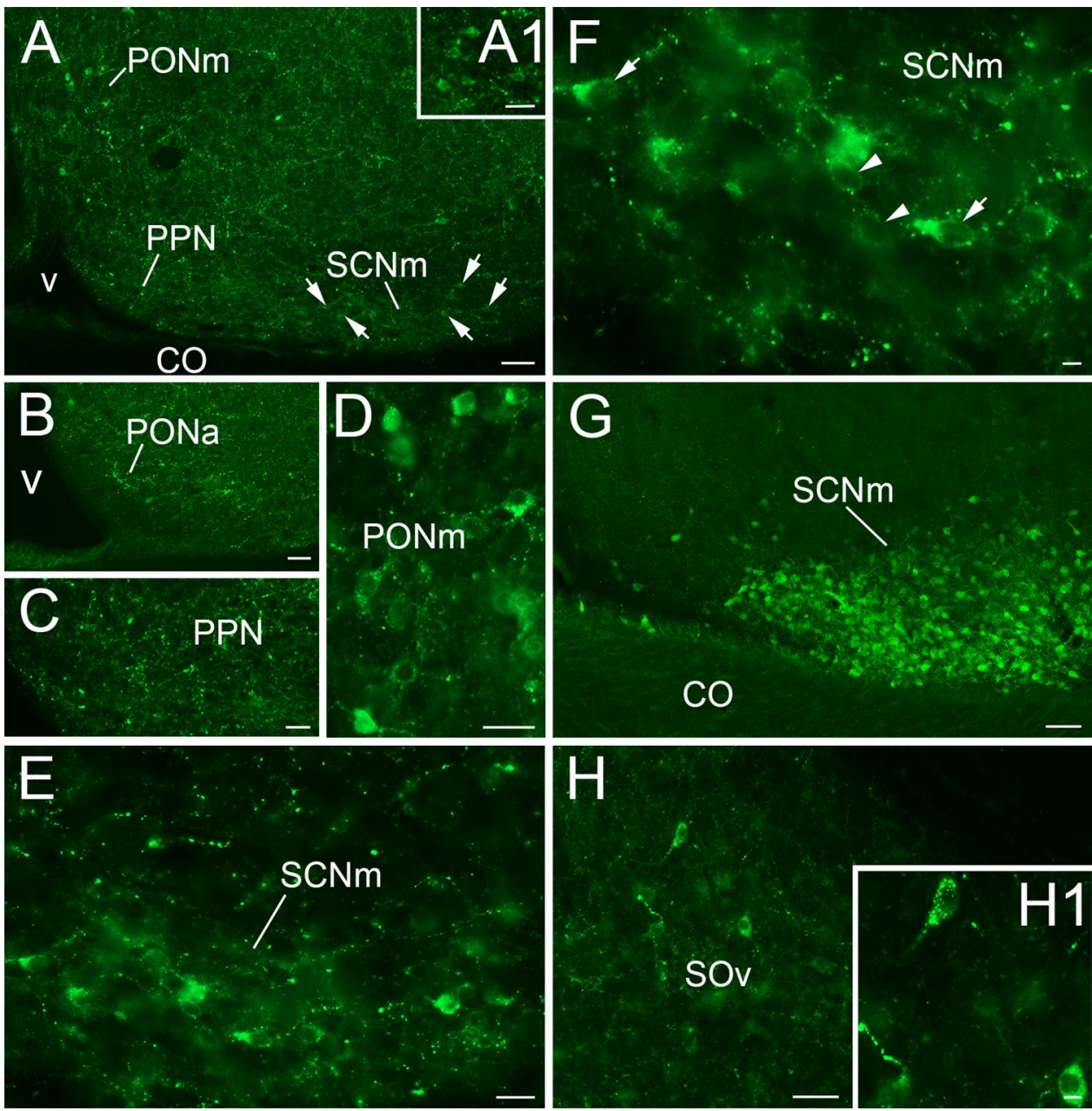

CART- (Fig. 7a, d, g, j) and TH- (Fig. 7b, e, h, k) immunoreactive neurons were found in the PONm (Fig. 7a-f) and LHN (Fig. 7g-1), no colocalization observed. Intensely labelled both CART- (Fig. 8a, d, g, j) and mesotocin- (Fig. 8b, e, h, k) immunoreactive neurons were seen in the PVN (Fig. 8a-f) and SOv (Fig. 8g-1). Whereas only few PVN CART neurons co-expressed the mesotocin (Fig. 8c, f), all SOv CART neurons were mesotocin-immunoreactive (Fig. 8i, 1). Similar to previously reported innervation of NPY fibers to DMN (Rastogi et al. 2013), we found NPY-immunoreactivity in the DMN where CART cells reside (Fig. 9A-C); few CART-immunoreactive neurons of DMN were in close contact with NPY-immunoreactive fibers (Fig. 9D-F, d-f). Distinct CART- (Fig. 9G, J, M, P), NPY-(Fig. 9H, K), and $\alpha-\mathrm{MSH}($ Fig. $9 \mathrm{~N}, \mathrm{Q})$ immunoreactive cells and fibers were found in the IH (Fig. 9G-I, M-O) and IN (Fig. 9J-L, P-R) of redheaded buntings. Isolated neurons in IH co-expressed CART and NPY (Fig. 9G-I, g-i), but no co-expression was observed in the IN neurons (Fig. 9J-L, j-l). A great proportion of CART neurons in both IH (Fig. 9M-O, m-o) and IN (Fig. 9P-R, p-r) co-expressed the $\alpha$-MSH. Using a semiquantitative analysis, we found approximately $44.3 \pm 3.4 \%$
CART neurons in the PVN and all CART neurons in the SOv co-expressed mesotocin. Similarly, $82.2 \pm 3.7 \%$ CART neurons of IH and all CART neurons of IN co-expressed $\alpha-\mathrm{MSH}$

\section{Hypothalamic expression of CART: comparison between seasonal states}

Distinct CART-immunoreactive cells and fibers were observed in the PONa (Fig. 10), SCNm, SCNv, AN, PVN, SOv, and DMN of all birds. No significant difference $(P>0.05)$ was observed in the percent fluorescent area of CART immunoreactivity or the CART-immunoreactive cell numbers between three photo-induced seasonal states (Table 3). However, CART immunoreactivity was drastically altered in the PONm (Fig. 11), LHN (Fig. 12), IH (Fig. 13D-F, J, L) and IN (Fig. 13G-I, K, M) of birds between the NMB, PMB, and MB states. Compared to $\mathrm{NMB}$, a significant increase in the percent fluorescent area of CART-immunoreactivity was found in the PONm (Fig. 11C-E, F; PMB vs. NMB: $P<0.001$ and MB vs. NMB: $P<0.001$ ), LHN (Fig. 12C-I; PMB: $P<0.01$ and 


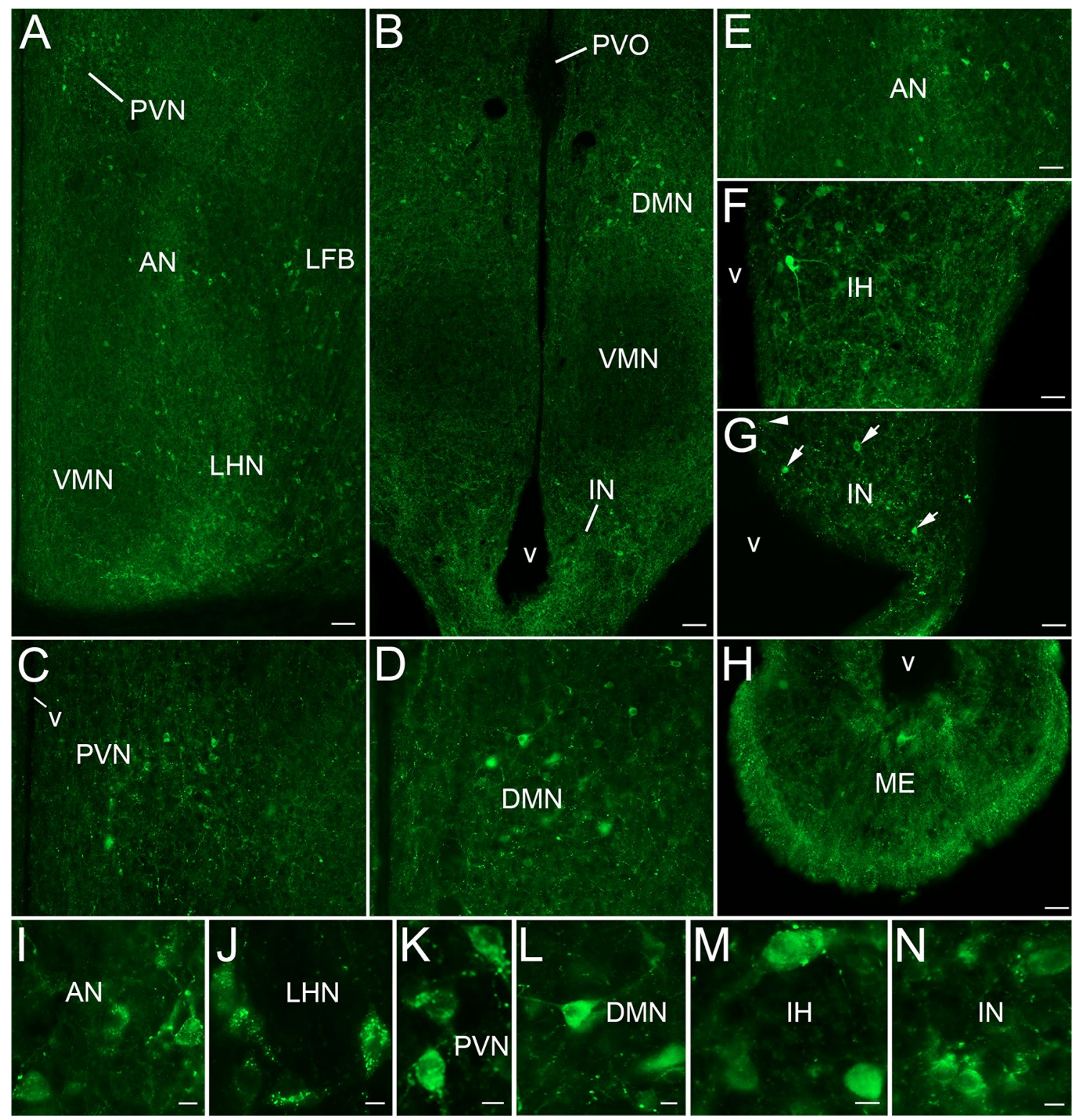

Fig. 6 Fluorescence photomicrographs showing CART-immunoreactive cells and fibers in the hypothalamus of E. bruniceps. Low-magnification photomicrographs showing CART-immunoreactive neurons and fibers in the hypothalamic paraventricular nucleus (PVN), anterior hypothalamic nucleus (AN), and lateral hypothalamic nucleus (LHN) (A), and nucleus dorsomedialis (DMN) and ventromedialis (VMN) hypothalami, and infundibular (IN) nuclei (B). Magnified view of CART-immunoreactive neurons in the PVN (C), DMN (D)

MB: $P<0.001$ vs NMB), IH (Fig. 13D-F, j; PMB and MB: $P<0.001$ vs. NMB), and IN (Fig. 13G-I, K; PMB: $P<0.05$ and MB: $P<0.001$ vs. NMB) of birds in the PMB and MB states. Whereas the number of CART-immunoreactive cells in the LHN (Fig. 12C-H, J) and IN (Fig. 13G-I, M) were similar between NMB and PMB states $(P>0.05)$. In the PONm, higher number of CART-immunoreactive cells were observed during $\mathrm{PMB}$ and $\mathrm{MB}$ states as compared to and AN (E). High-magnification photomicrographs of the CARTimmunoreactive cells and fibers in the AN $(\mathbf{I}), \operatorname{LHN}(\mathbf{J}), \operatorname{PVN}(\mathbf{C}, \mathbf{K})$, DMN (D, L), IH (F, M), and IN (g, n). Strong (arrows) and weak (arrowhead) CART cells in IN (g). H CART-immunoreactive fibers are seen in the median eminence (ME) particularly in its external zone. $L F B$ lateral forebrain bundle; $P V O$ paraventricular organ; $v$ ventricle. Scale bar $=50 \mu \mathrm{m}$ in $\mathbf{A}, \mathbf{B} ; 25 \mu \mathrm{m} \mathbf{C}-\mathbf{H}$; and $10 \mu \mathrm{m}$ in $\mathbf{I}-\mathbf{N}$

that in NMB state (Fig. 11C-E, G; $P<0.001$ ). The CARTimmunoreactive cells were significantly higher $(P<0.001)$ in the LHN (Fig. 12E, H, J), IH (Fig. 13F, L), and IN (Fig. 13I, M) during MB than the other two states. Interestingly, the CART-immunoreactive elements in the PONm and IH showed different response, as compared to those in the LHN and IN. We found significantly more $(P<0.001)$ CART-immunoreactive cells in the PONm (Fig. 11D, G) 
Fig. 7 Double immunofluorescence photomicrographs of the medial preoptic (PONm) and lateral hypothalamic (LHN) nuclei of E. bruniceps showing the association between CART(green) and TH (red)-containing systems. Low (A-C; G-I) and high (D-F; J-L) magnification photomicrographs showing CART- and TH-immunoreactive cells and fibers in PONm and LHN. None of the CART neurons in the PONm and LHN contain TH $(\mathbf{C}, \mathbf{F}, \mathbf{I}, \mathbf{L}) . v$ ventricle; $V M N$ nucleus ventromedialis hypothalamic. Scale bar $=50 \mu \mathrm{m}$ in $\mathbf{A}-\mathbf{C}$ and $\mathbf{G}-\mathbf{I}$, $25 \mu \mathrm{m}$ in $\mathbf{D}-\mathbf{F}$ and $\mathbf{J}-\mathbf{L}$
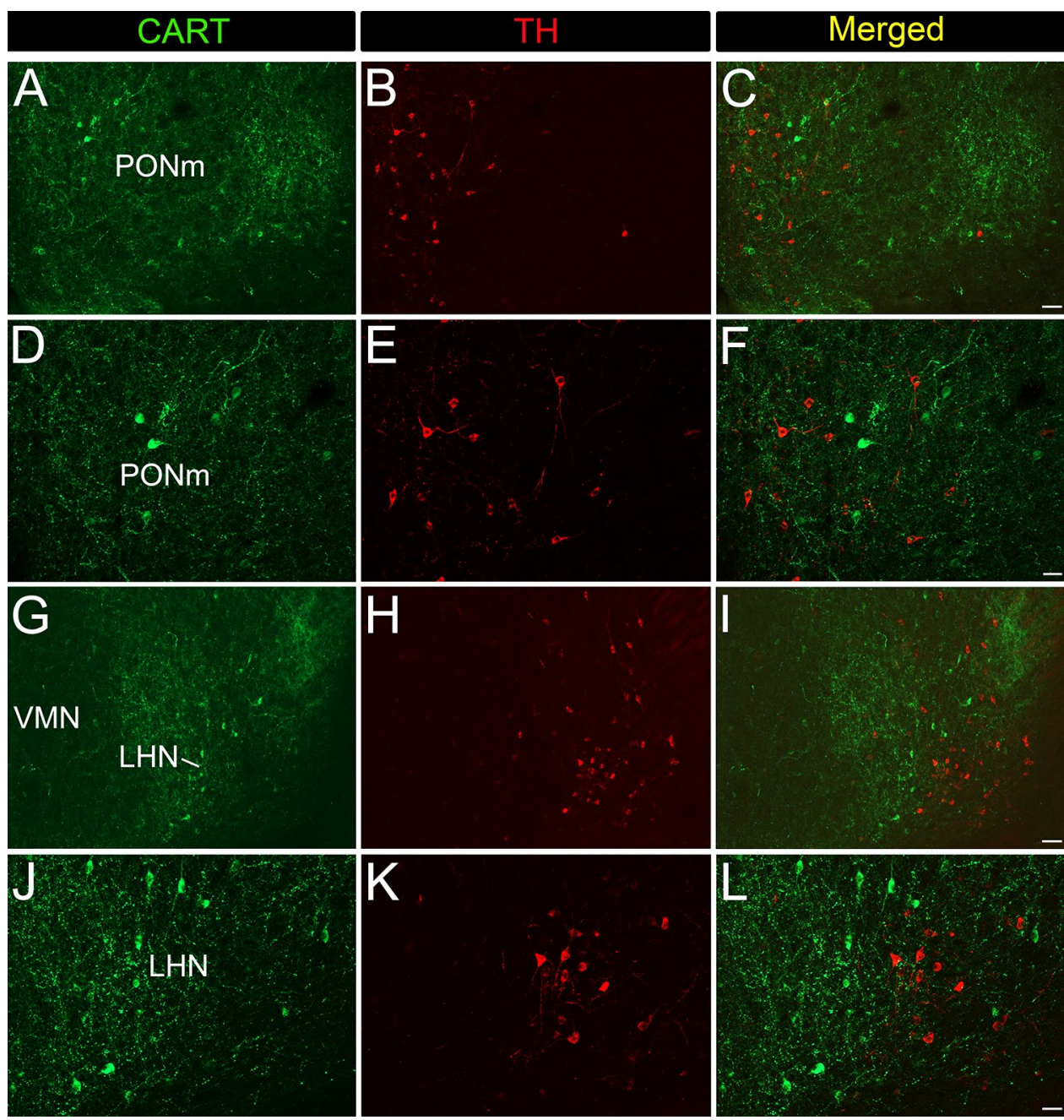

and IH (Fig. 13E, L) under LD-induced PMB, as compared to the SD-induced NMB state. Compared to this, the number of CART-immunoreactive cells in the LHN and IN did not change with transition from SD-induced NMB to LDinduced PMB state.

\section{Discussion}

We show LD-induced development of migratory (e.g., hyperphagia, Zugunruhe) and reproductive (testicular recrudescence) phenotypes, consistent with previous results on photostimulated states in captive redheaded buntings (Rani et al. 2005; Sharma et al. 2018). However, present study importantly asked a specific question as to whether CART immunoreactivity, particularly in the hypothalamus, was altered with photostimulated seasonal response in migratory buntings. We addressed this by the measurement of CART immunoreactivity in different hypothalamic nuclei, and evaluation of its possible association with photostimulated seasonal phenotypes in buntings. As pre-requisite, we were confident that rabbit polyclonal anti-CART antiserum that we used specifically, localized the hypothalamic CART-containing system in buntings. This was based on several lines of evidence: (1) This antiserum has been used and validated for CART immunoreactivity in the brain of other birds, including zebra finches (Singh et al. 2016a). (2) The Western blot analysis of the At20 cells transfected with wild-type proCART (Yanik et al. 2006) as well as the hypothalamic tissue of zebra finches (Singh et al. 2016a) showed two prominent CART-immunoreactive bands of approximately 8 and $5 \mathrm{kDa}$, with latter representing the biologically active CART (55-102) fragment of the CART. (3) Hypothalamic sections of buntings incubated with present CART antiserum pre-adsorbed with control CART peptide showed no immunofluorescence signal at the end of the procedure. Although the forms of CART expressed in the brain of redheaded bunting cannot be known from this study, we believe, based on results from another songbird (zebra finch; Singh et al. 2016a) that the antiserum we used recognized a biologically active form of the CART in this bird species as well. In fact, very little is known of the structure and 
Fig. 8 Double immunofluorescence photomicrographs of the hypothalamic paraventricular (PVN) and ventral supraoptic, (SOv) nuclei of E. bruniceps showing the association between CART- (green) and mesotocin (red)-containing systems. Low $(\mathbf{A}-\mathbf{C} ; \mathbf{G}-\mathbf{I})$ and high (D-F; J-L) magnification photomicrographs showing CARTand mesotocin-immunoreactive cells and fibers in the PVN and SOv. While few CART neurons co-expressing mesotocin are seen in the PVN (arrows; A-F), all CART neurons contain mesotocin in the SOv (G-L). Colocalized cells appear yellow due to colour mixing. $\mathrm{CO}$, optic chiasma; $v$, ventricle. Scale bars $=25 \mu \mathrm{m}$ in $\mathbf{A}-\mathbf{C}$ and $\mathbf{G}-\mathbf{I}$, $10 \mu \mathrm{m}$ in $\mathbf{D}-\mathbf{F}$ and $\mathbf{J}-\mathbf{L}$
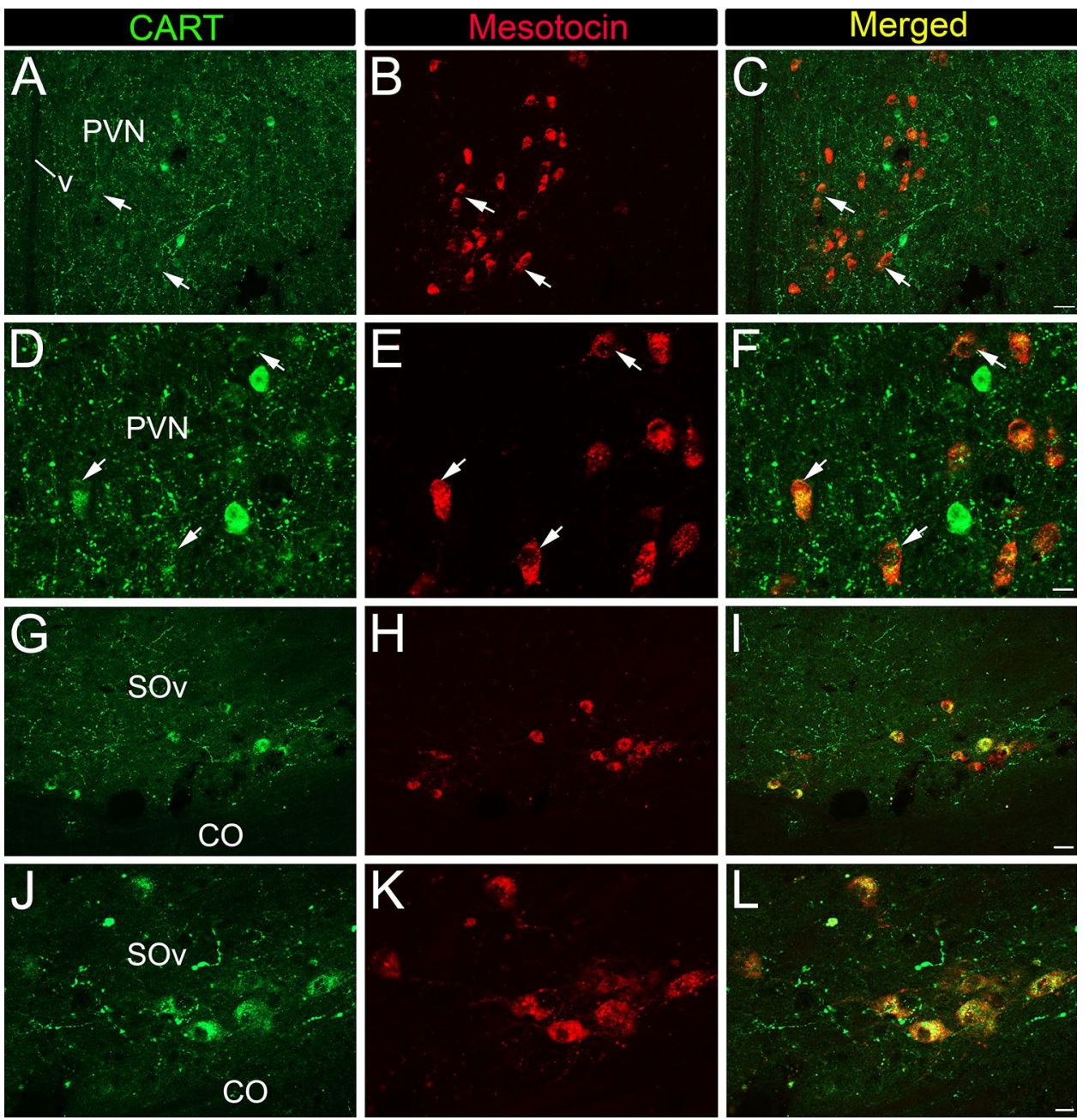

forms of CART peptide in birds. To CART genes ( $c$ CARTI and $c C A R T 2$ ) have been characterized in chickens (Cai et al. 2015). The $c C A R T 1$ is predicted to give rise to bioactive cCART1 (42-89) and cCART1(49-89) peptides (Cai et al. 2015). While cCART2 generate one biologically active cCART2(51-91) peptide fragment, cCART1 peptides show 96-98\% sequence similarity with those in humans, mice and rats (Cai et al. 2015). cCART1 mRNA is expressed in the hypothalamus of chickens and is down-regulated by fasting (Cai et al. 2015). On the other hand, cCART2 (51-89) showed only $59 \%$ sequence similarly with chicken CART1(49-89) and human CART(49-89) and might not play a significant physiological role in chicken (Cai et al. 2015).

Hypothalamic CART-immunoreactivity of buntings was comparable to that found in other birds (Singh et al. 2016a; Gutierrez-Ibanez et al. 2016). So, based on other bird study, we can speculate CART playing a significant physiological roles in redheaded buntings. For example, in ad libitum fed broiler chickens, hypothalamic CART mRNA levels were higher in males than the females
(Caughey et al. 2018). Similarly, both acute and chronic fasting enhanced AgRP/NPY, but not POMC/CART, mRNA levels in the mediobasal hypothalamus of Japanese quails and chicks (Boswell et al. 2002; Higgins et al. 2010; Phillips-Singh et al. 2003; Song et al. 2012; Higgins et al. 2010; Caughey et al. 2018). Hence, our data showing the co-expression of CART and $\alpha$-MSH peptides in the IN and IH neurons of redheaded buntings is a novel observation. The presence of NPY neurons and co-expression of CART and $\alpha$-MSH peptides further substantiate the homology of IN with mammalian arcuate nucleus, in which they are suggested to play a role in the regulation of the energy balance. In the hypothalamus of bunting, while few PVN CART neurons were mesotocin, but all the SOv CART neurons co-expressed the mesotocin. This is similar to the presence of CART (Singh et al. 2016a; Gutierrez-Ibanez et al. 2016) and mesotocin (Bons 1980; Goodson et al. 2012; Hall et al. 2015) neurons found in the PVN and SOv of birds. These nuclei in mammals co-express the CART and oxytocin (Vrang et al. 1999; Elias et al. 2001), and the administration of CART peptide induces cFos expression 
Fig. 9 Double immunofluorescence photomicrographs of the nucleus dorsomedialis (DMN), inferior (IH) and infundibular (IN) hypothalamic nuclei of $E$. bruniceps showing the association between CART- (green; A, $\mathbf{D}, \mathbf{G}, \mathbf{J}, \mathbf{M}, \mathbf{P})$ and either NPY(red, B, E, H, K) or $\alpha-\mathrm{MSH}$ (red; N, Q)-containing systems. Magnified views of double labeled cells/cells contacted by fibers are shown in insets (d-r). CART-immunoreactive cells in the DMN are contacted by NPY-immunoreactive fibers (A-F, d-f), whereas NPYimmunoreactive cells in the IH (G-I), and IN (J-L, j-l) are contacted by CART-immunoreactive fibers. A CART and NPY double labeled neuron in IH (arrow, G-I, g-i). Colocalization of $\alpha-\mathrm{MSH}$ and CART in IH (M-O, m-o) and IN (P-R, $\mathrm{p}-\mathrm{r}$ ) neurons (arrows). Isolated CART neurons not co-expressing $\alpha$-MSH (arrowheads) in the IH (M-O). Colocalized cells appear yellow due to colour mixing. $v$ ventricle. Scale bar $=25 \mu \mathrm{m}$ in $\mathbf{A}-\mathbf{R}$, and $5 \mu \mathrm{m}$ in $\mathrm{d}-\mathrm{r}$

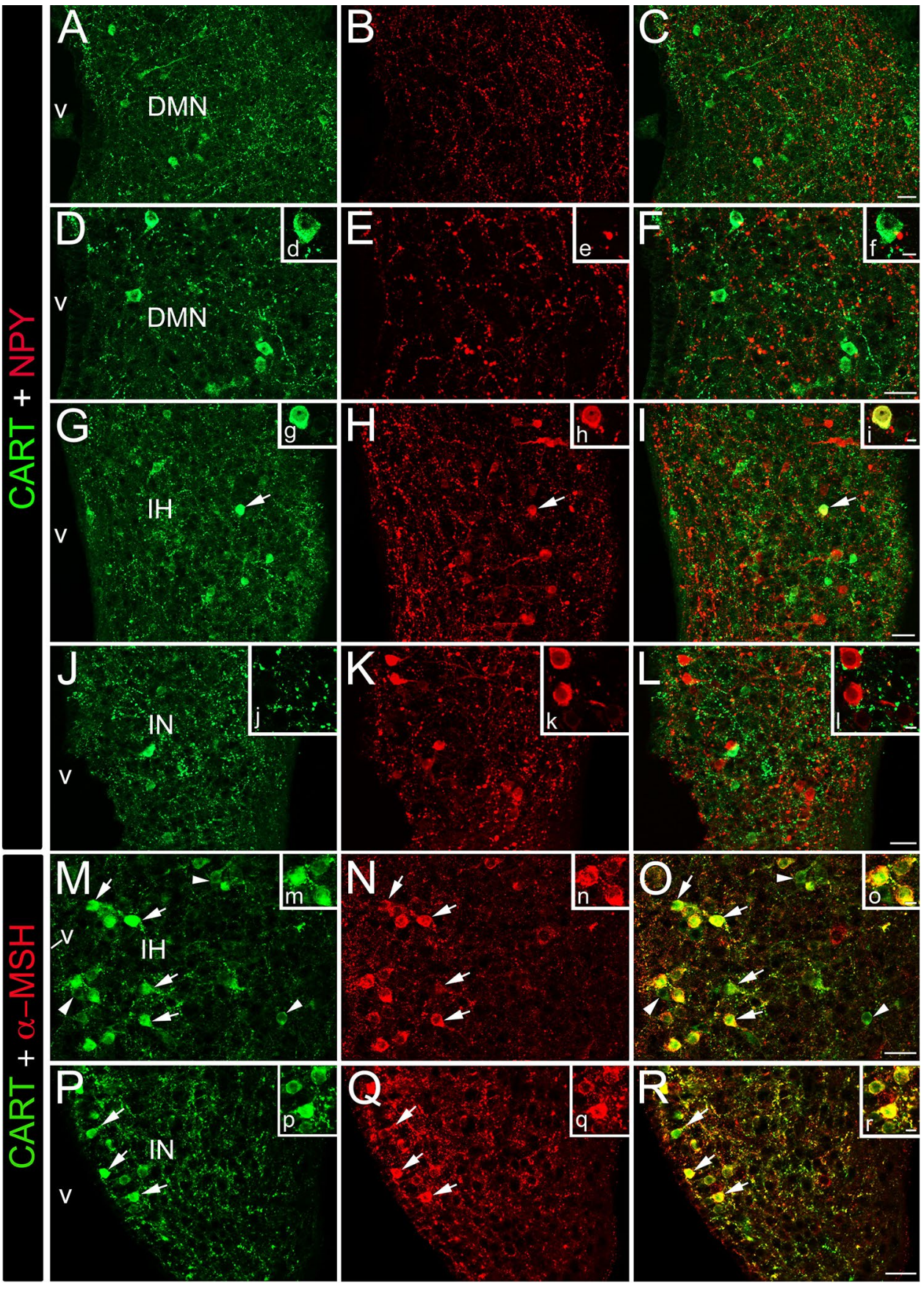

in oxytocin but not in the vasopressin neurons (Vrang et al. 2000).

The key question of this study was whether the hypothalamic CART-containing system showed correlation with the photostimulated seasonal response. We answered this by the measuring the CART immunoreactivity in important hypothalamic areas that have been suggested to be involved in the initiation and maintenance of the photoperiodic seasonal response in migratory song birds, including the hypothalamic POA, PVN, IN, DMH, LHN, tanycytes lining the third ventricle and median eminence that detect, transmit and integrate the environment cues (Stevenson and Kumar 2017). The involvement of PVN, tanycytes lining of third ventricle, and median eminence, which are closely associated with the paraventricular organ that senses the photoperiod information via deep brain photoreceptors, in photoperiod-induced seasonal responses have been described in different species including migratory redheaded buntings (Majumdar et al. 2014) and reviewed several times (García-Fernández et al. 2015; Surbhi and Kumar 2015). There is also the phase-inversion in the neuronal activity, as shown by c-Fos immunohistochemistry 
Fig. 10 Schematic of the coronal section of the brain (A) and the photomicrograph of the Nissl stained section of preoptic area (POA) (B, C) of E. bruniceps showing the neuroanatomical location of the anterior preoptic nucleus (PONa). Fluorescence photomicrographs showing the effect of transition from short day (SD) to long day (LD) on CART-immunoreactivity in the PONa of E. bruniceps. CARTimmunoreactive cells and fibers in the PONa (D-F) of birds in the three different phases [nonmigratory/non-breeding (NMB; D), pre-migratory/pre-breeding (PMB; E), and migratory/breeding (MB; F)]. Rectangles on the right in (A) represents the region used for image analysis of the percent fluorescent area of immunoreactivity. Semiquantitative image analysis of the percent fluorescent area of CART-immunoreactivity (G) and number of CARTimmunoreactive cells $(\mathbf{H})$ in the PONa of birds collected during $\mathrm{NMB}, \mathrm{PMB}$, and MB phases. $P O R$ preoptic recess; $C O$ optic chiasm; TSM septopallial mesencephalic tract; $n s$ nonsignificant. Scale bar $=50 \mu \mathrm{m}$ in $\mathbf{C}-\mathbf{E}$ and $100 \mu \mathrm{m}$ in $(\mathbf{B})$
Table 3 CART

immunoreactivity in the hypothalamus of the $E$.

bruniceps not responding to during different photostimulated seasonal states
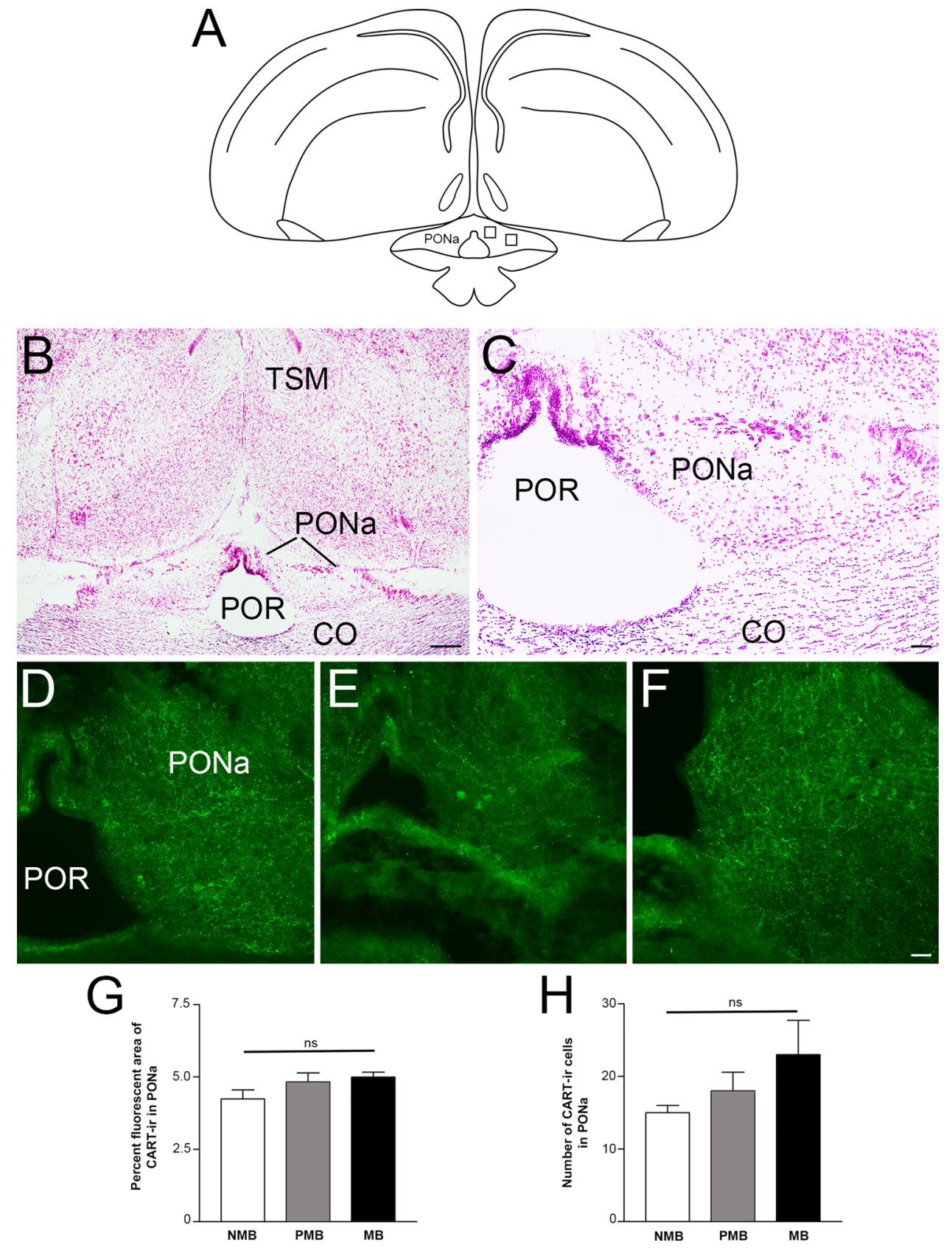

G
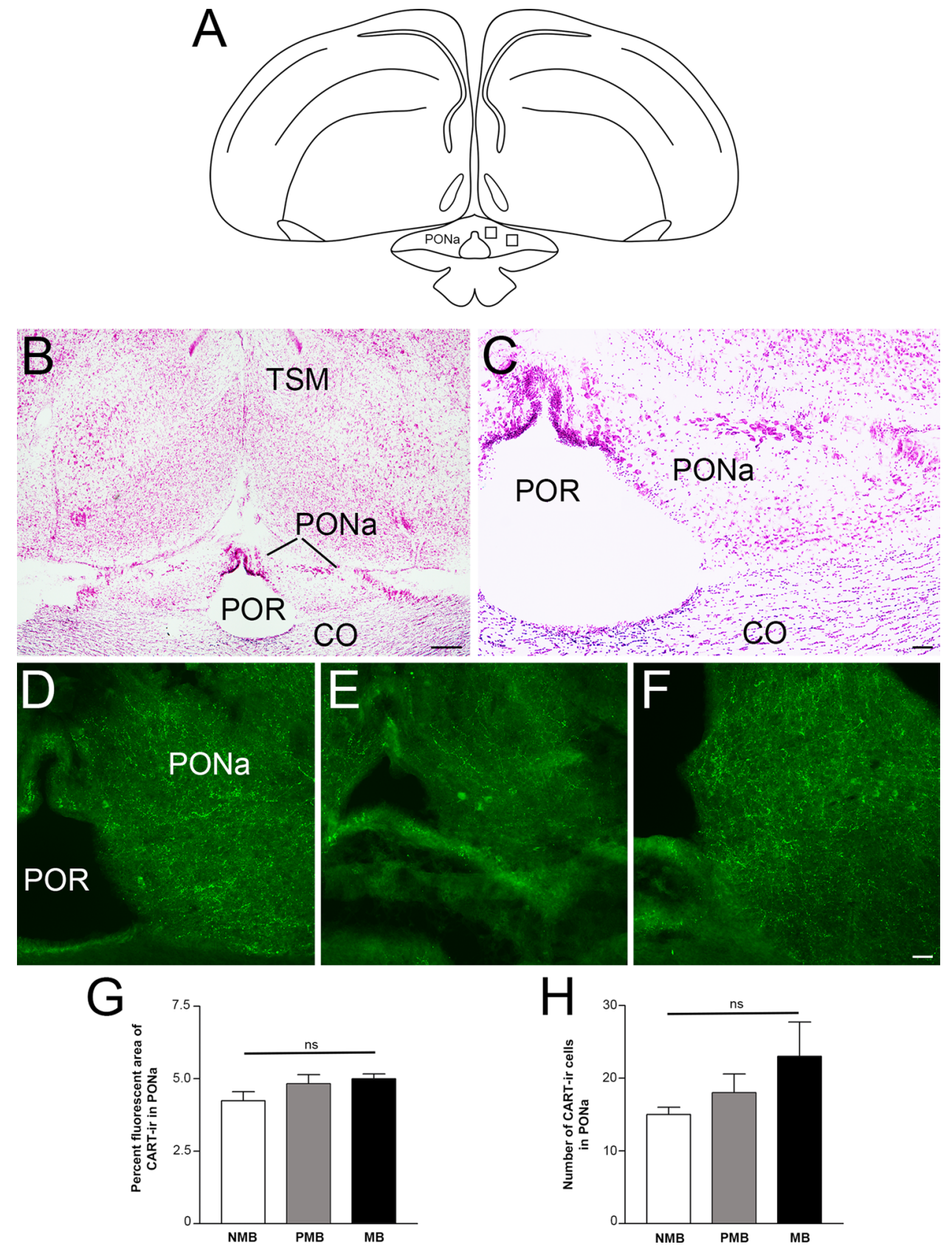

$\mathrm{H}$
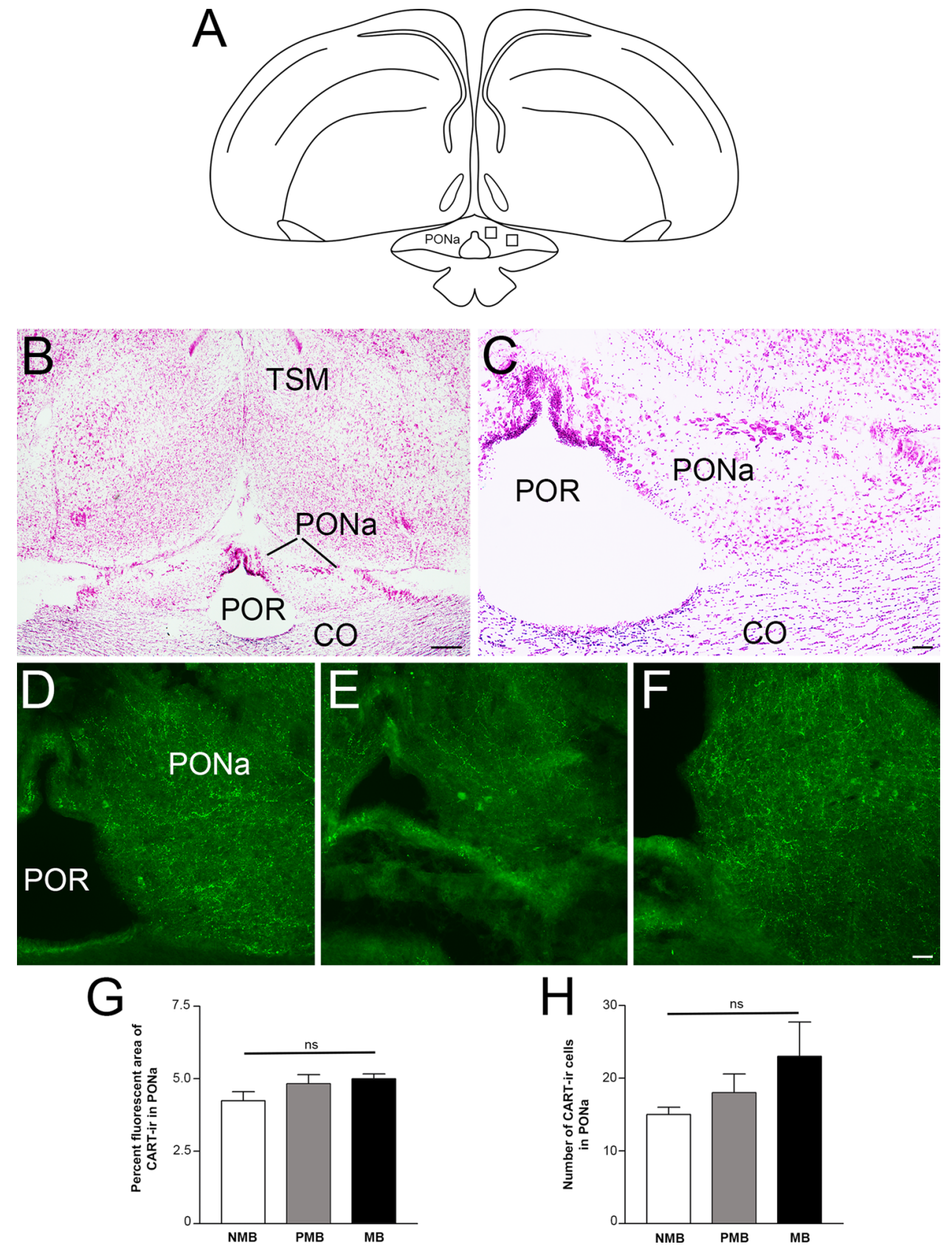

\begin{tabular}{lccccccc}
\hline $\begin{array}{l}\text { Hypotha- } \\
\text { lamic areas }\end{array}$ & \multicolumn{2}{l}{ Cell number } & & & \multicolumn{3}{l}{ Percent fluorescent area } \\
\cline { 2 - 3 } & NMB & PMB & MB & & NMB & PMB & MB \\
\hline SCNm & $45 \pm 5.4$ & $58.75 \pm 6.2$ & $80 \pm 15.1$ & & $5.51 \pm 1.0$ & $7.14 \pm 1.03$ & $4.97 \pm 0.92$ \\
SCNv & $26.25 \pm 5.5$ & $38.75 \pm 2.4$ & $47.5 \pm 12.7$ & & $4.01 \pm 1.0$ & $5.93 \pm 0.78$ & $4.84 \pm 0.68$ \\
PVN & $204 \pm 9.4$ & $200 \pm 6.5$ & $230 \pm 10.4$ & & $8.60 \pm 1.2$ & $7.98 \pm 1.04$ & $8.51 \pm 1.48$ \\
SOv & $96 \pm 13.4$ & $125 \pm 11.7$ & $117 \pm 8.5$ & & $3.84 \pm 0.71$ & $4.50 \pm 0.86$ & $5.1 \pm 0.62$ \\
AH & $55 \pm 5.8$ & $73.33 \pm 4.4$ & $73.33 \pm 6.0$ & & $7.97 \pm 0.6$ & $7.22 \pm 0.80$ & $8.65 \pm 1.47$ \\
DMN & $186.7 \pm 12.0$ & $190 \pm 17.3$ & $213.3 \pm 20.3$ & & $11.75 \pm 0.8$ & $11.71 \pm 1.7$ & $12.1 \pm 1.71$ \\
\hline
\end{tabular}


Fig. 11 Schematic of the coronal section of the brain (A) and the photomicrograph of the Nissl stained section of preoptic area (B) of E. bruniceps showing the neuroanatomical location of the medial preoptic nucleus (PONm). Fluorescence photomicrographs showing the effect of transition from short day (SD) to long day (LD) on CART-immunoreactivity in the PONm of E. bruniceps. CARTimmunoreactive cells and fibers in the PONm (C-E) of birds in the three different phases [nonmigratory/non-breeding (NMB; C), pre-migratory/pre-breeding $(\mathrm{PMB} ; \mathrm{D})$, and migratory/breeding $(\mathrm{MB} ; \mathbf{E})]$. Rectangles on the right in (A) represents the regions used for image analysis of the percent fluorescent area of immunoreactivity. Semiquantitative image analysis of the percent fluorescent area of CART-immunoreactivity (F) and number of CART-immunoreactive cells $(\mathbf{G})$ in the $\mathrm{PONm}$ of birds collected during NMB, $\mathrm{PMB}$, and MB phases. $C O$ optic chiasma; $P P N$ periventricular preoptic nucleus; $S C N m$ medial suprachiasmatic nucleus; $n s$ non-significant; $* * * P<0.001$. Scale bar $=50 \mu \mathrm{m}$ in $\mathbf{C}-\mathbf{E}$; $100 \mu \mathrm{m}$ in $\mathbf{B}$
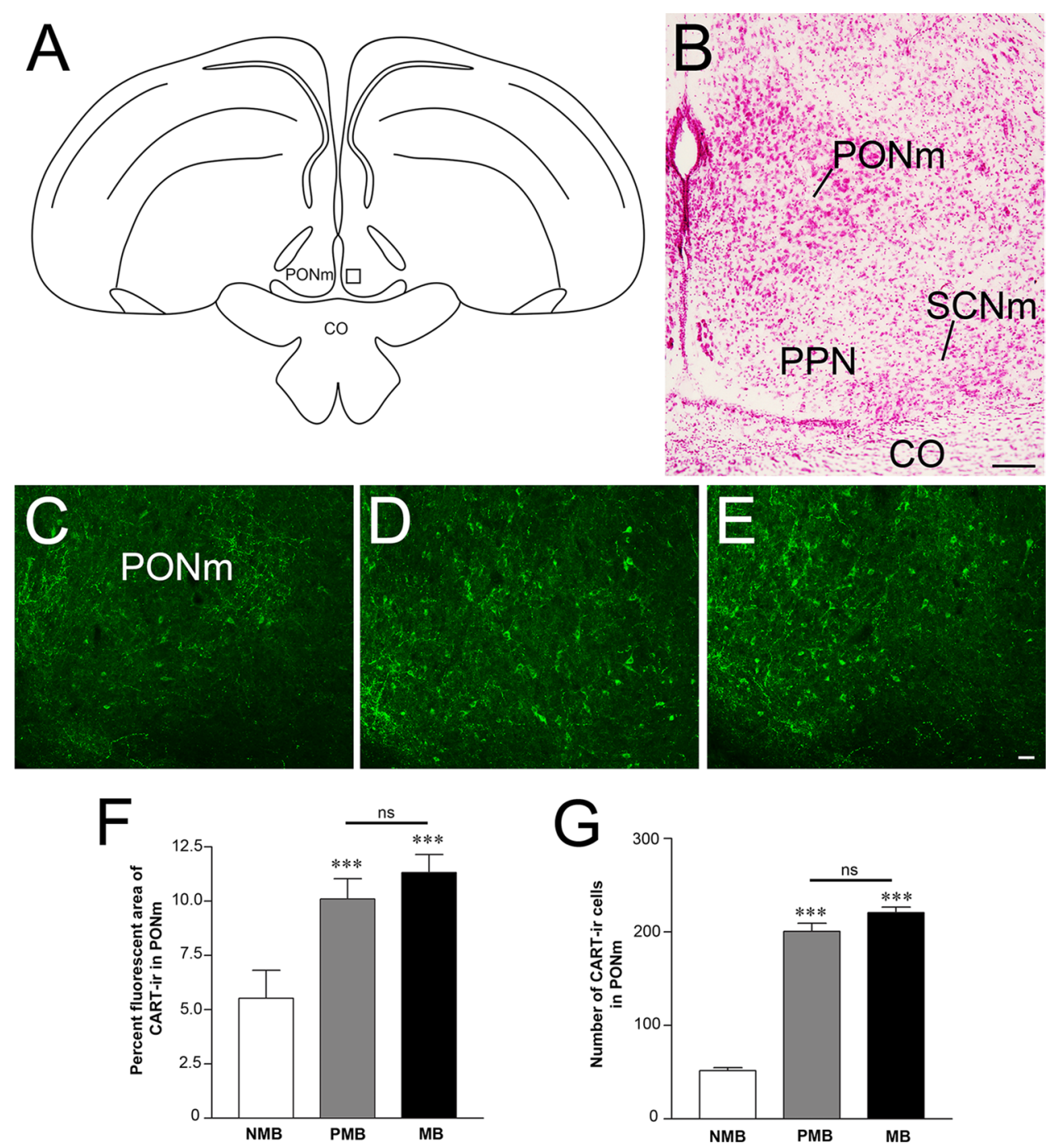

of $\mathrm{MBH}$ region in parallel with phase-inversion in the behavior during migratory state with the onset of night migratory activity (Rastogi et al. 2013). This suggested the involvement of $\mathrm{MBH}$ in the photo-neuroendocrine regulation of seasonal response in migratory birds (Rastogi et al. 2013). However, there is no direct evidence for receptors in the POA, IN, DMH and LHN, except that of the $\mathrm{GnRH} / \mathrm{GnIH}$ receptors, which are crucial for the initiation and maintenance of the photoperiodic gonadal seasonal response in birds. We, therefore, correlated hypothalamic discrete populations of CART neurons and widely distributed CART fibers with photoperiod-induced seasonal response in migratory redheaded buntings, as supported by the following observations. There was a marked increase in the percent fluorescent area of CART-immunoreactivity in the PONm, LHN, IH and IN of birds in photostimulated $\mathrm{MB}$, compared to the non-stimulated NMB state, consistent with the suggested role of CART in feeding and energy homeostasis in birds and other vertebrates (Elias et al.
2001; Subhedar et al. 2011, 2014; Akash et al. 2014; Lau and Herzog 2014; Singh et al. 2016a). The IN neurons in the hypothalamus of both migratory (Singh et al. 2013) and resident (Singh et al. 2016a) birds show NPY immunoreactivity, and CART regulates the NPY neurons (Singh et al. 2016a). Increased NPY immunoreactivity in the IN was also found in photostimulated blackheaded buntings (Rastogi et al. 2013). In zebra finch IN, CART-immunoreactive fibers were found to innervate NPY-immunoreactive cells, NPY- and CART-immunoreactive showed energystatus-dependent changes, and the treatment with CART peptide inhibited fasting-induced increase in the NPY expression (Singh et al. 2016a). This is overall consistent with the involvement of CART cells in the hypothalamic arcuate nucleus in the regulation of energy balance in rats (Vrang et al. 1999; Vrang 2006). However, we would like caution that we have demonstrated only alternation in the activity of CART neurons by the measurement of the overall peptide content of cells, which does not distinguish 
Fig. 12 Schematic of the coronal section (A) and photomicrograph of the Nisslstained section (B) of the brain of E. bruniceps showing the neuroanatomical location of the lateral hypothalamic nucleus (LHN). The LHN is demarcated with dashed line on the left. Fluorescence photomicrographs showing the effect of transition from short day (SD) to long day (LD) on CART immunoreactivity in the LHN of E. bruniceps. CART-immunoreactive cells and fibers in the LHN (C-H) [low (C-E) and high $(\mathbf{F}-\mathbf{H})$ magnification] of birds in the three different phases [non-migratory/non-breeding (NMB; C, F), pre-migratory/ pre-breeding $(\mathrm{PMB} ; \mathbf{D}, \mathbf{G})$, and migratory/breeding (MB; $\mathbf{E}, \mathbf{H})]$. The rectangles on the right side of the schematic (A) represents the regions used for image analysis of the percent fluorescent area of immunoreactivity. Semiquantitative image analysis of the percent fluorescent area of CART immunoreactivity (I) and number of CART-immunoreactive cells (J) in the LHN of birds collected during $\mathrm{NMB}, \mathrm{PMB}$, and $\mathrm{MB}$ phases. GLv nucleus geniculatus lateralis, pars ventralis; $L F B$ lateral forebrain bundle; $v$ ventricle; $n s$ non-significant; $* * P<0.01$, *** $P<0.001$. Scale bar $=100 \mu \mathrm{m}$ in $\mathbf{B} ; 50 \mu \mathrm{m}$ in $\mathbf{C}-\mathbf{E}$; and $25 \mu \mathrm{m}$ in $\mathbf{F}-\mathbf{H}$
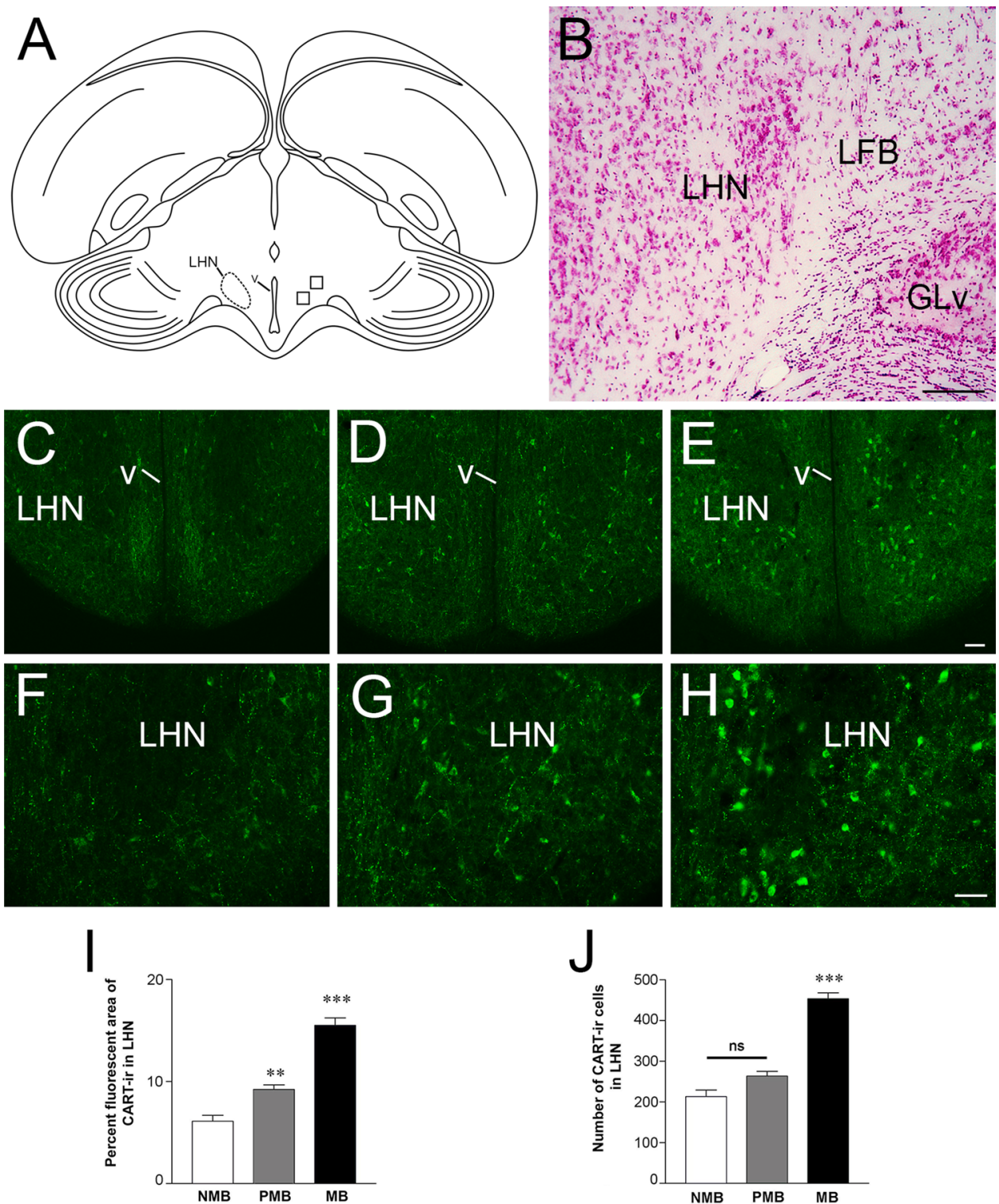

whether the increase peptide level was because of the enhanced synthesis of the peptide or its decreased release from cell bodies, or both.

Interestingly, we also found CART-immunoreactive in SCN of buntings, similar to that in pigeons (GutierrezIbanez et al. 2016) but not zebra finches (Singh et al. 2016a; Gutierrez-Ibanez et al. 2016). Taken together, the CART-immunoreactive in SCNm and SCNv, which constitute avian SCN (Yoshimura et al. 2001; Rastogi et al. 2013), suggests the involvement of CART in the circadian clock-dependent phtotoperiodic responses in buntings. Perhaps, CART acts as neuromodulator of the circadian rhythm mediated photoperiodic induction by its direct effects, or by indirect effects on the daily rhythm in hypothalamic neurotransmitters that indeed show changes with photoperiod-induced transition in the seasonal states
(Mishra et al. 2018). Similar to zebra finches (Singh et al. 2016a), CART-immunoreactivity in PVN indicated its probable role in the regulation of energy balance, as suggested in mammals. The PVN CART neurons in mice are hypophysiotropic (Kádár et al. 2010), and they co-express TRH in rats (Raptis et al. 2004). CART inhibits TRHinduced prolactin secretion but not the TRH-induced TSH secretion (Raptis et al. 2004). We also found CART-immunoreactivity cells in SOv of redheaded buntings, similar to zebra finches (Singh et al. 2016a) but unlike in pigeons (Gutierrez-Ibanez et al. 2016). We speculate CART SOv neurons play a role in the neuroendocrine regulation and/ or modulation of hypothalamic nonapeptides in redheaded buntings, as in rats in which CART was found co-expressed with oxytocin- and vasopressin-containing neurons in the supraoptic nucleus of rat (Vrang et al. 1999; 
Fig. 13 Schematics of the coronal sections $(\mathbf{A}, \mathbf{B})$ and photomicrograph of the Nisslstained section $(\mathbf{C})$ of the brain of E. bruniceps showing the neuroanatomical location of the inferior hypothalamic (IH) and infundibular (IN) nuclei in the mediobasal hypothalamus. The IH (A) and IN (B) are demarcated with dashed line on the left. Fluorescence photomicrographs showing the effect of transition from short day (SD) to long day (LD) on CART-immunoreactive cells and fibers in the IH (D-F) and IN (G-I) of E. bruniceps in the non-migratory/non-breeding (NMB) (D, G), pre-migratory/ prebreeding $(\mathrm{PMB})(\mathbf{E}, \mathbf{H})$, and migratory/breeding $(\mathrm{MB})(\mathbf{F}$, i) phases. Strong (arrows) and weak (arrowheads) CART cells in IN (G-I). The rectangles on the right of the schematics A and $\mathrm{B}$ represents the regions used for image analysis of the percent fluorescent area of immunoreactivity. Semiquantitative image analysis of the percent fluorescent area $(\mathbf{J}, \mathbf{K})$ and number of CARTimmunoreactive cells $(\mathbf{L}, \mathbf{M})$ in the IH $(\mathbf{J}, \mathbf{L})$ and IN $(\mathbf{K}, \mathbf{M})$ during each phase. $v$ ventricle; $n s$ non-significant; $* P<0.05$, $* * P<0.01, * * * P<0.001$. Scale bar $=100 \mu \mathrm{m}$ in $\mathbf{c}$; and $25 \mu \mathrm{m}$ in $\mathbf{D}-\mathbf{I}$
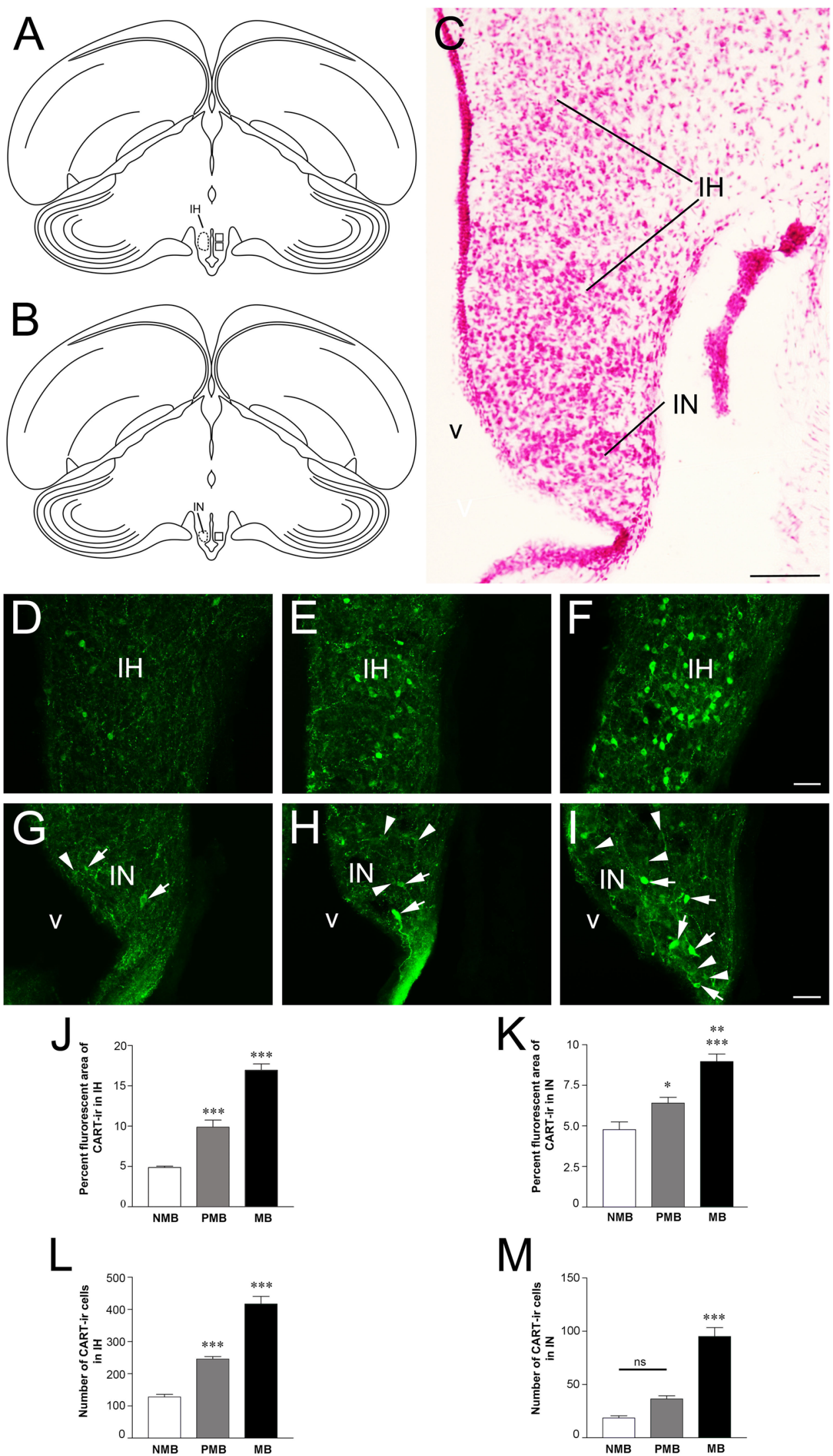
Elias et al. 2001), with dense CART-immunoreactivity terminals in the neurohypophysis (Koylu et al. 1997).

Distinct CART-immunoreactive neurons were observed in the POA of redheaded bunting. Using Nissl staining and immunohistochemistry with specific neuronal markers, Brandstätter and Abraham (2003) showed that the POA of birds has three components including the anterior (PONa), medial (PONm), and periventricular (PPN) preoptic nuclei. We observed that the POA in buntings was organized into PONa, PONm, and PPN, and CART-immunoreactive cells seen in the PONa and PONm, not in PPN. Distinct CARTimmunoreactivity was also observed in the POA of zebra finches (Singh et al. 2016a) and piegons (Gutierrez-Ibanez et al. 2016). Both, the CART-immunoreactive cell number and percent fluorescent area in PONm, not PONa, showed distinct changes with photoperiod-induced seasonal states in redheaded buntings. Although it cannot be known from this study, we speculate interaction of CART with GnRH-I in PONm; GnRH-I-immunoreactivity in the POA has been shown correlated with the reproductive state in buntings (Surbhi et al. 2016). This is consistent with reported interaction of GnRH neurons and CART axons in the POA of rats (True et al. 2013); retrograde neuronal tracing study in rats also support this (Rondini et al. 2004). CART seem to have a potent stimulatory role in the regulation of POA GnRH neurons in mammals, as suggested by increased neuronal firing of GnRH neurons in the brain slices treated with CART peptide (True et al. 2013). Furthermore, avian IN is homologous to the mammalian arcuate nucleus, and IN/IH-lesioned birds cease to show photostimulated gonadal recrudescence (Kuenzel 2000), and IN is also involved in the regulation of energy balance in birds (Singh et al. 2016a; Boswell and Dunn 2017). We, therefore, suggest that enhanced activity of IN CART neurons projecting to POA modulated photoperiodic seasonal response in redheaded buntings. Increased CART-immunoreactivity in IN/IH in MB state might also be involved in inhibiting the food intake either directly or via its action on NPY neurons. This is consistent with the finding from zebra finches that IN NPY neurons (contacted by CART fibers) responded to food deprivation and refeeding, and treatment CART peptide treatment suppressed food deprivation-induced increased NPY expression in IN (Singh et al. 2016a).

Likewise, we associate DMN/LHN CART-immunoreactive neurons with both daily and seasonal metabolic responses in redheaded buntings. For example, an increased c-Fos-immunoreactivity was observed in DMN in photostimulated migratory blackheaded buntings (Rastogi et al. 2013). In mammals, DMN also plays a role in circadian rhythms of wakefulness, feeding, locomotor activity and serum corticosteroid levels (Chou et al. 2003). DMNlesioned rats showed hypophagia and loss in body mass (Bellinger and Bernardis 2002), CART mRNA expression was observed in DMN, leptin administration induced c-Fos expression in DMN neurons (Elias et al. 2001) and DMN seemed to play a role in the regulation of food-entrainable circadian rhythms (Gooley et al. 2006). We speculate that LHN CART neurons might have a role in the motivational response related to hyperphagia prior to the migration in redheaded buntings. This is based on the role of lateral hypothalamic area in controlling the feeding behaviour, and reward and reinforcement processes in mammals (Elmquist et al. 1999; Stuber and Wise 2016; Petrovich 2018). In fact, the lateral hypothalamic area is a part of distributed feeding neuronal network that integrates different feeding drives and motivates eating (Coons et al. 1965; Petrovich 2018). The arcuate nucleus and lateral hypothalamic area CART neurons exert differential effects on the energy homeostasis (Lau et al. 2018). Whereas anorexigenic but anabolic effects were observed following activation of arcuate nucleus CART neurons, the orexigenic but catabolic effects were seen after CART neuronal activation in the lateral hypothalamus (Lau et al. 2018; Farzi et al. 2018). In mice, the lateral hypothalamic CART regulates energy expenditure during dark phase when the animals are active, whereas the stimulation of the lateral hypothalamus in the presence of CART enhanced the physical activity (Farzi et al. 2018). In redheaded buntings, the development of Zugunruhe was accompanied with increased LHN CART immunoreactivity, suggesting a role of CART in energy expenditure and appetite-associated motivation in photostimulated buntings. Although the number of CART neurons in LHN of redheaded buntings during NMB and PMB states was comparable, increased percent fluorescent area of CART-immunoreactivity was observed in LHN during PMB state. We suggest that there is an increased synthesis of CART peptide in the LHN neurons during PMB state.

\section{Conclusions}

CART-immunoreactive system seems to be discretely organized in the POA and hypothalamus of redheaded buntings with CART cells distributed in crucial brain regions including AN, PVN, SOv, LHN, DMN, IH and IN. Demonstration of CART-immunoreactive cells in both subdivisions of SCN and several cells in IN, and co-expression of CART and $\alpha-\mathrm{MSH}$ in the IH/IN seemed novel findings, not previously observed in other birds. Importantly, CART-immunoreactivity in the PONm, LHN, IH, and IN was altered with photoinduction of seasonal response under long days in redheaded buntings. The activation of the CART-immunoreactive system in PONm, LHN, IH, and IN in photostimulated states might be taken to suggest that there is an alteration in the activity of CART-containing systems with photoperiod-induced seasonal responses associated with 
migration and reproduction (e.g., food intake and energy balance, and gonadal growth and development) in migratory redheaded buntings. However, further studies are needed to show a cause-effect relationship of CART with photoperiodic seasonal responses in migratory birds.

Acknowledgement The study is supported by the grant from the Department of Biotechnology (DBT), New Delhi, India (Grant number BT/PR4984/MED/30/752/2012). We also used Carl Zeiss Axioimager M2 fluorescence microscope for this study, which was made available by the Science and Engineering Research Board (SERB), Department of Science and Technology (DST), New Delhi (Grant number SR/SO/ AS-83/2010). O.S. thanks NISER, Bhubaneswar and Department of Biotechnology (DBT), Govt. of India, New Delhi for the financial support. The timely completion of work was possible due to all the support extended by NISER during the COVID-19 pandemic.

Funding Department of Biotechnology (DBT), New Delhi, India (Grant number BT/PR4984/MED/30/752/2012).

Code availability Not applicable.

\section{Compliance with ethical standards}

Conflict of interest The authors declare that they have no conflict of interest.

Ethics approval All experiments were performed in accordance with the guidelines of the Institutional Animal Ethics Committee (IAEC), Department of Zoology, University of Lucknow, Lucknow, and NISER, Bhubaneswar, India.

\section{Consent to participate Not applicable.}

Consent for publication The manuscript is new, reports novel findings and has not been submitted elsewhere for publication. All authors approve the publication of this manuscript.

Availability of data and material The data that support the findings of this study are available from the corresponding author upon reasonable request.

\section{References}

Abercrombie M (1946) Estimation of nuclear population from microtome sections. Anat Rec 94:239-247. https://doi. org/10.1002/ar.1090940210

Agatsuma R, Ramenofsky M (2006) Migratory behaviour of captive white-crowned sparrows, Zonotrichia leucophrys gambelii, differs during autumn and spring migration. Behaviour 143:1219-1240. https://doi.org/10.1163/156853906778691586

Akash G, Kaniganti T, Tiwari NK et al (2014) Differential distribution and energy status-dependent regulation of the four CART neuropeptide genes in the zebrafish brain. J Comp Neurol 522:22662285. https://doi.org/10.1002/cne.23532

Ali S, Dillon RS (1974) Handbook of the Birds of India and Pakistan. Oxford University Press, Bombay London New York
Bairlein F (2002) How to get fat: nutritional mechanisms of seasonal fat accumulation in migratory songbirds. Naturwissenschaften 89:1-10. https://doi.org/10.1007/s00114-001-0279-6

Barsh GS, Schwartz MW (2002) Genetic approaches to studying energy balance: perception and integration. Nat Rev Genet 3:589-600. https://doi.org/10.1038/nrg862

Bellinger LL, Bernardis LL (2002) The dorsomedial hypothalamic nucleus and its role in ingestive behavior and body weight regulation: Lessons learned from lesioning studies. Physiol Behav 76:431-442. https://doi.org/10.1016/S0031-9384(02)00756-4

Bons N (1980) The topography of mesotocin and vasotocin systems in the brain of the domestic mallard and Japanese quail: immunocytochemical identification. Cell Tissue Res 213:37-51. https ://doi.org/10.1007/BF00236919

Boswell T (2005) Regulation of energy balance in birds by the neuroendocrine hypothalamus. J Poult Sci 42:161-181. https://doi. org/10.2141/jpsa.42.161

Boswell T, Dunn IC (2017) Regulation of agouti-related protein and pro-opiomelanocortin gene expression in the avian arcuate nucleus. Front Endocrinol (Lausanne) 8:75. https://doi. org/10.3389/fendo.2017.00075

Boswell T, Li Q, Takeuchi S (2002) Neurons expressing neuropeptide $\mathrm{Y}$ mRNA in the infundibular hypothalamus of Japanese quail are activated by fasting and co-express agouti-related protein mRNA. Brain Res Mol Brain Res 100:31-42. https://doi. org/10.1016/S0169-328X(02)00145-6

Bottjer SW (1993) The distribution of tyrosine hydroxylase immunoreactivity in the brains of male and female zebra finches. $J$ Neurobiol. https://doi.org/10.1002/neu.480240105

Brandstätterr R, Abraham U (2003) Hypothalamic circadian organization in birds. I. Anatomy, functional morphology, and terminology of the suprachiasmatic region. Chronobiol Int 20:637655. https://doi.org/10.1081/cbi-120023343

Budki P, Rani S, Kumar V (2009) Food deprivation during photosensitive and photorefractory life-history stages affects the reproductive cycle in the migratory red-headed bunting, Emberiza bruniceps. J Exp Biol 212:225-230. https://doi.org/10.1242/ jeb.024190

Cai G, Mo C, Huang L et al (2015) Characterization of the two CART genes (CART1 and CART2) in chickens (Gallus gallus). PLoS ONE 10:e0127107. https://doi.org/10.1371/journ al.pone.0127107

Calle M, Kozicz T, van der Linden E et al (2006) Effect of starvation on Fos and neuropeptide immunoreactivities in the brain and pituitary gland of Xenopus laevis. Gen Comp Endocrinol 147:237246. https://doi.org/10.1016/j.ygcen.2006.01.007

Cardot J, Griffond B, Risold P-Y et al (1999) Melanin-concentrating hormone-producing neurons in birds. J Comp Neurol 411:239-256. https://doi.org/10.1002/(SICI)1096-9861(19990 823)411:2\%3c239::AID-CNE5\%3e3.0.CO;2-7

Caughey SD, Wilson PW, Mukhtar N et al (2018) Sex differences in basal hypothalamic anorectic and orexigenic gene expression and the effect of quantitative and qualitative food restriction. Biol Sex Differ 9:20. https://doi.org/10.1186/s13293-018-0178-6

Chokchaloemwong D, Prakobsaeng N, Sartsoongnoen N et al (2013) Mesotocin and maternal care of chicks in native Thai hens ( $\mathrm{Gal}$ lus domesticus). Horm Behav. https://doi.org/10.1016/j.yhbeh .2013.04.010

Chou TC, Scammell TE, Gooley JJ et al (2003) Critical role of dorsomedial hypothalamic nucleus in a wide range of behavioral circadian rhythms. J Neurosci 23:10691-10702. https://doi. org/10.1523/JNEUROSCI.23-33-10691.2003

Chronwall BM, DiMaggio DA, Massari VJ et al (1985) The anatomy of neuropeptide-Y-containing neurons in rat brain. Neuroscience 15:1159-1181. https://doi.org/10.1016/0306-4522(85)90260-X 
Coons EE, Levak M, Miller NE (1965) Lateral hypothalamus: learning of food-seeking response motivated by electrical stimulation. Science 80(150):1320-1321. https://doi.org/10.1126/scien ce. 150.3701 .1320

Elias CF, Lee CE, Kelly JF et al (2001) Characterization of CART neurons in the rat and human hypothalamus. J Comp Neurol 432:1-19. https://doi.org/10.1002/cne.1085

Elmquist JK, Maratos-Flier E, Saper CB, Flier JS (1998) Unraveling the central nervous system pathways underlying responses to leptin. Nat Neurosci 1:445-450. https://doi.org/10.1038/2164

Elmquist JK, Elias CF, Saper CB (1999) From lesions to leptin: hypothalamic control of food intake and body weight. Neuron 22:221232. https://doi.org/10.1016/S0896-6273(00)81084-3

Farzi A, Lau J, Ip CK et al (2018) Arcuate nucleus and lateral hypothalamic CART neurons in the mouse brain exert opposing effects on energy expenditure. Elife 7:e36494. https://doi.org/10.7554/ eLife.36494

García-Fernández JM, Cernuda-Cernuda R, Davies WIL et al (2015) The hypothalamic photoreceptors regulating seasonal reproduction in birds: a prime role for VA opsin. Front Neuroendocrinol 37:13-28. https://doi.org/10.1016/j.yfrne.2014.11.001

Gombash SE, Manfredsson FP, Mandel RJ et al (2014) Neuroprotective potential of pleiotrophin overexpression in the striatonigral pathway compared with overexpression in both the striatonigral and nigrostriatal pathways. Gene Ther 21:682-693

Goodson JL, Kelly AM, Kingsbury MA (2012) Evolving nonapeptide mechanisms of gregariousness and social diversity in birds. Horm Behav 61:239-250. https://doi.org/10.1016/j.yhbeh.2012.01.005

Gooley JJ, Schomer A, Saper CB (2006) The dorsomedial hypothalamic nucleus is critical for the expression of food-entrainable circadian rhythms. Nat Neurosci 9:398-407. https://doi.org/10.1038/ nn1651

Gutekunst C-A, Stewart EN, Gross RE (2010) Immunohistochemical distribution of plexinA4 in the adult rat central nervous system. Front Neuroanat 4:1-17. https://doi.org/10.3389/fnana .2010 .00025

Gutierrez-Ibanez C, Iwaniuk AN, Jensen M et al (2016) Immunohistochemical localization of cocaine- and amphetamine-regulated transcript peptide (CARTp) in the brain of the pigeon (Columba livia) and zebra finch (Taeniopygia guttata). J Comp Neurol 524:3747-3773. https://doi.org/10.1002/cne.24028

Gwinner E, Czeschlik D (1978) On the significance of spring migratory restlessness in caged birds. Oikos 30:364-372. https://doi. org/10.2307/3543485

Hall ZJ, Healy SD, Meddle SL (2015) A role for nonapeptides and dopamine in nest-building behaviour. J Neuroendocrinol 27:158165. https://doi.org/10.1111/jne. 12250

Higgins SE, Ellestad LE, Trakooljul N et al (2010) Transcriptional and pathway analysis in the hypothalamus of newly hatched chicks during fasting and delayed feeding. BMC Genomics 11:162. https ://doi.org/10.1186/1471-2164-11-162

Ho T, Jobling AI, Greferath U et al (2015) Vesicular expression and release of ATP from dopaminergic neurons of the mouse retina and midbrain. Front Cell Neurosci 9:389. https://doi.org/10.3389/ fncel.2015.00389

Honda K, Kamisoyama H, Saneyasu T et al (2007) Central administration of insulin suppresses food intake in chicks. Neurosci Lett 423:153-157. https://doi.org/10.1016/j.neulet.2007.07.004

Kabelik D, Schrock SE, Ayres LC, Goodson JL (2011) Estrogenic regulation of dopaminergic neurons in the opportunistically breeding zebra finch. Gen Comp Endocrinol 173:96-104. https://doi. org/10.1016/j.ygcen.2011.04.026

Kádár A, Sánchez E, Wittmann G et al (2010) Distribution of hypophysiotropic thyrotropin-releasing hormone (TRH)-synthesizing neurons in the hypothalamic paraventricular nucleus of the mouse. J Comp Neurol 518:3948-3961. https://doi.org/10.1002/ cne. 22432

Koylu EO, Couceyro PR, Lambert PD et al (1997) Immunohistochemical localization of novel CART peptides in rat hypothalamus, pituitary and adrenal gland. J Neuroendocrinol 9:823-833. https ://doi.org/10.1046/j.1365-2826.1997.00651.x

Kristensen P, Judge ME, Thim L et al (1998) Hypothalamic CART is a new anorectic peptide regulated by leptin. Nature 393:72-76. https://doi.org/10.1038/29993

Kuenzel WJ (2000) Central nervous system regulation of gonadal development in the avian male. Poult Sci. https://doi.org/10.1093/ ps/79.11.1679

Kuenzel WJ, van Tienhoven A (1982) Nomenclature and location of avian hypothalamic nuclei and associated circumventricular organs. J Comp Neurol 206:293-313. https://doi.org/10.1002/ cne.902060309

Kumar V, Wingfield JC, Dawson A et al (2010) Biological clocks and regulation of seasonal reproduction and migration in birds. Physiol Biochem Zool 83:827-835. https://doi.org/10.1086/652243

Lambert PD, Couceyro PR, McGirr KM et al (1998) CART peptides in the central control of feeding and interactions with neuropeptide Y. Synapse 29:293-298. https://doi.org/10.1002/(SICI)10982396(199808)29:4\%3c293::AID-SYN1\%3e3.0.CO;2-0

Lau J, Herzog H (2014) CART in the regulation of appetite and energy homeostasis. Front Neurosci 8:313. https://doi.org/10.3389/fnins .2014 .00313

Lau J, Farzi A, Qi Y et al (2018) CART neurons in the arcuate nucleus and lateral hypothalamic area exert differential controls on energy homeostasis. Mol Metab 7:102-118. https://doi.org/10.1016/j. molmet.2017.10.015

Lázár G, Calle M, Roubos EW, Kozicz T (2004) Immunohistochemical localization of cocaine- and amphetamine-regulated transcript peptide in the central nervous system of the frog, Rana esculenta. J Comp Neurol 477:324-339. https://doi.org/10.1002/cne.20264

Loh K, Herzog H, Shi Y-C (2015) Regulation of energy homeostasis by the NPY system. Trends Endocrinol Metab 26:125-135. https ://doi.org/10.1016/j.tem.2015.01.003

Majumdar G, Yadav G, Rani S, Kumar V (2014) A photoperiodic molecular response in migratory redheaded bunting exposed to a single long day. Gen Comp Endocrinol 204:104-113. https://doi. org/10.1016/j.ygcen.2014.04.013

Malik S, Rani S, Kumar V (2004) Wavelength dependency of lightinduced effects on photoperiodic clock in the migratory blackheaded bunting, Emberiza melanocephala. Chronobiol Int 21:367-384. https://doi.org/10.1081/CBI-120038742

Meddle SL, Follett BK (1997) Photoperiodically driven changes in Fos expression within the basal tuberal hypothalamus and median eminence of Japanese quail. J Neurosci 17:8909-8918. https://doi. org/10.1523/JNEUROSCI.17-22-08909.1997

Mercer JG, Tups A (2003) Neuropeptides and anticipatory changes in behaviour and physiology: seasonal body weight regulation in the siberian hamster. Eur J Pharmacol 480:43-50. https://doi. org/10.1016/j.ejphar.2003.08.091

Mishra I, Singh D, Kumar V (2017) Seasonal alterations in the daily rhythms in hypothalamic expression of genes involved in the photoperiodic transduction and neurosteroid-dependent processes in migratory blackheaded buntings. J Neuroendocrinol. https://doi. org/10.1111/jne.12469

Mishra I, Singh D, Kumar V (2018) Temporal expression of c-fos and genes coding for neuropeptides and enzymes of amino acid and amine neurotransmitter biosynthesis in retina, pineal and hypothalamus of a migratory songbird: evidence for circadian rhythmdependent seasonal responses. Neuroscience 371:309-324. https ://doi.org/10.1016/j.neuroscience.2017.12.016 
Okumura T, Yamada H, Motomura W, Kohgo Y (2000) Cocaineamphetamine-regulated transcript (CART) acts in the central nervous system to inhibit gastric acid secretion via brain corticotropinreleasing factor system. Endocrinology 141:2854-2860. https:// doi.org/10.1210/endo.141.8.7588

Petrovich GD (2018) Lateral hypothalamus as a motivation-cognition interface in the control of feeding behavior. Front Syst Neurosci. https://doi.org/10.3389/fnsys.2018.00014

Phillips-Singh D, Li Q, Takeuchi S et al (2003) Fasting differentially regulates expression of agouti-related peptide, pro-opiomelanocortin, prepro-orexin, and vasoactive intestinal polypeptide mRNAs in the hypothalamus of Japanese quail. Cell Tissue Res 313:217-225. https://doi.org/10.1007/s00441-003-0755-8

Rani S, Singh S, Misra M et al (2005) Daily light regulates seasonal responses in the migratory male redheaded bunting, Emberiza bruniceps. J Exp Zool A Comp Exp Biol 303:541-550. https:// doi.org/10.1002/jez.a.187

Rani S, Malik S, Trivedi AK et al (2006) A circadian clock regulates migratory restlessness in the blackheaded bunting, Emberiza melanocephala. Curr Sci 91:1093-1096

Raptis S, Fekete C, Sarkar S et al (2004) Cocaine- and amphetamineregulated transcript co-contained in thyrotropin-releasing hormone (TRH) neurons of the hypothalamic paraventricular nucleus modulates TRH-induced prolactin secretion. Endocrinology 145:1695-1699. https://doi.org/10.1210/en.2003-1576

Rastogi A, Kumari Y, Rani S, Kumar V (2011) Phase inversion of neural activity in the olfactory and visual systems of a night-migratory bird during migration. Eur J Neurosci 34:99-109. https://doi. org/10.1111/j.1460-9568.2011.07737.x

Rastogi A, Kumari Y, Rani S, Kumar V (2013) Neural correlates of migration: activation of hypothalamic $\operatorname{clock}(\mathrm{s})$ in and out of migratory state in the blackheaded bunting Emberiza melanocephala. PLoS ONE 8:e70065. https://doi.org/10.1371/journ al.pone. 0070065

Rondini TA, Baddini SP, Sousa LF et al (2004) Hypothalamic cocaineand amphetamine-regulated transcript neurons project to areas expressing gonadotropin releasing hormone immunoreactivity and to the anteroventral periventricular nucleus in male and female rats. Neuroscience 125:735-748. https://doi.org/10.1016/j.neuro science.2003.12.045

Sen S, Parishar P, Pundir AS et al (2019) The expression of tyrosine hydroxylase and DARPP-32 in the house crow (Corvus splendens) brain. J Comp Neurol 527:1-36. https://doi.org/10.1002/ cne. 24649

Sharma A, Singh D, Malik S et al (2018) Difference in control between spring and autumn migration in birds: insight from seasonal changes in hypothalamic gene expression in captive buntings. Biol Sci. https://doi.org/10.1098/rspb.2018.1531

Singh D, Kumari Y, Rastogi A et al (2013) Neuropeptide Y mRNA and peptide in the night-migratory redheaded bunting brain. Cell Tissue Res 354:551-562. https://doi.org/10.1007/s00441-013-1667-x

Singh D, Trivedi AK, Rani S et al (2015) Circadian timing in central and peripheral tissues in a migratory songbird: dependence on annual life-history states. FASEB J 29:4248-4255. https://doi. org/10.1096/fj.15-275339

Singh O, Kumar S, Singh U et al (2016a) Cocaine- and amphetamineregulated transcript peptide (CART) in the brain of zebra finch, Taeniopygia guttata: Organization, interaction with neuropeptide Y, and response to changes in energy status. J Comp Neurol 524:3014-3041. https://doi.org/10.1002/cne.24004

Singh O, Kumar S, Singh U et al (2016b) Role of isotocin in the regulation of the hypophysiotropic dopamine neurones in the preoptic area of the catfish Clarias batrachus. J Neuroendocrinol. https:// doi.org/10.1111/jne. 12441

Singh O, Pradhan D, Nagalakashmi B et al (2019) Thyrotropinreleasing hormone (TRH) in the brain and pituitary of the teleost,
Clarias batrachus and its role in regulation of hypophysiotropic dopamine neurons. J Comp Neurol 527:1070-1101. https://doi. org/10.1002/cne.24570

Singru PS, Mazumdar M, Sakharkar AJ et al (2007) Immunohistochemical localization of cocaine- and amphetamine-regulated transcript peptide in the brain of the catfish, Clarias batrachus (Linn.). J Comp Neurol 502:215-235. https://doi.org/10.1002/ cne. 21295

Song Z, Liu L, Yue Y et al (2012) Fasting alters protein expression of AMP-activated protein kinase in the hypothalamus of broiler chicks (Gallus gallus domesticus). Gen Comp Endocrinol 178:546-555. https://doi.org/10.1016/j.ygcen.2012.06.026

Stevenson TJ, Kumar V (2017) Neural control of daily and seasonal timing of songbird migration. J Comp Physiol A Neuroethol Sens Neural Behav Physiol 203:399-409. https://doi.org/10.1007/s0035 9-017-1193-5

Stuber GD, Wise RA (2016) Lateral hypothalamic circuits for feeding and reward. Nat Neurosci 19:198-205. https://doi.org/10.1038/ nn. 4220

Subhedar N, Barsagade VG, Singru PS et al (2011) Cocaine- and amphetamine-regulated transcript peptide (CART) in the telencephalon of the catfish, Clarias gariepinus: Distribution and response to fasting, 2-deoxy-D-glucose, glucose, insulin, and leptin treatments. J Comp Neurol 519:1281-1300. https://doi. org/10.1002/cne.22569

Subhedar NK, Nakhate KT, Upadhya MA, Kokare DM (2014) CART in the brain of vertebrates: circuits, functions and evolution. Peptides 54:108-130. https://doi.org/10.1016/j.peptides.2014.01.004

Surbhi KV (2015) Avian photoreceptors and their role in the regulation of daily and seasonal physiology. Gen Comp Endocrinol 220:13-22. https://doi.org/10.1016/j.ygcen.2014.06.001

Surbhi RA, Rani S, Kumar V (2015) Seasonal plasticity in the peptide neuronal systems: potential roles of gonadotrophin-releasing hormone, gonadotrophin-inhibiting hormone, neuropeptide $\mathrm{Y}$ and vasoactive intestinal peptide in the regulation of the reproductive axis in subtropical Indian weaver birds. J Neuroendocrinol 27:357-369. https://doi.org/10.1111/jne.12274

Surbhi RA, Malik S et al (2016) Changes in brain peptides associated with reproduction and energy homeostasis in photosensitive and photorefractory migratory redheaded buntings. Gen Comp Endocrinol 230-231:67-75. https://doi.org/10.1016/j.ygcen .2016 .03 .031

Tachibana T, Takagi T, Tomonaga S et al (2003) Central administration of cocaine- and amphetamine-regulated transcript inhibits food intake in chicks. Neurosci Lett 337:131-134. https://doi. org/10.1016/S0304-3940(02)01321-6

Tomaszuk A, Simpson C, Williams G (1996) Neuropeptide Y, the hypothalamus and the regulation of energy homeostasis. Horm Res 46:53-58. https://doi.org/10.1159/000184996

Trivedi A, Kumar J, Rani S, Kumar V (2014) Annual life historydependent gene expression in the hypothalamus and liver of a migratory songbird: insights into the molecular regulation of seasonal metabolism. J Biol Rhythms 29:332-345. https://doi. org/10.1177/0748730414549766

True C, Verma S, Grove KL, Smith MS (2013) Cocaine- and amphetamine-regulated transcript is a potent stimulator of GnRH and kisspeptin cells and may contribute to negative energy balanceinduced reproductive inhibition in females. Endocrinology 154:2821-2832. https://doi.org/10.1210/en.2013-1156

Vrang N (2006) Anatomy of hypothalamic CART neurons. Peptides 27:1970-1980. https://doi.org/10.1016/j.peptides.2005.10.029

Vrang N, Larsen PJ, Clausen JT, Kristensen P (1999) Neurochemical characterization of hypothalamic cocaine- amphetamine-regulated transcript neurons. J Neurosci. https://doi.org/10.1523/JNEUR OSCI.19-10-j0006.1999 
Vrang N, Larsen PJ, Kristensen P, Tang-Christensen M (2000) Central administration of cocaine-amphetamine-regulated transcript activates hypothalamic neuroendocrine neurons in the rat. Endocrinology 141:794-801. https://doi.org/10.1210/endo.141.2.7295

Yanik T, Dominguez G, Kuhar MJ et al (2006) The Leu34Phe ProCART mutation leads to cocaine- and amphetamine-regulated transcript (CART) deficiency: a possible cause for obesity in humans. Endocrinology 147:39-43. https://doi.org/10.1210/ en.2005-0812

Yoshimura T, Yasuo S, Suzuki Y et al (2001) Identification of the suprachiasmatic nucleus in birds. Am J Physiol Regul Integr
Comp Physiol 280:R1185-R1189. https://doi.org/10.1152/ajpre gu.2001.280.4.R1185

Publisher's Note Springer Nature remains neutral with regard to jurisdictional claims in published maps and institutional affiliations. 